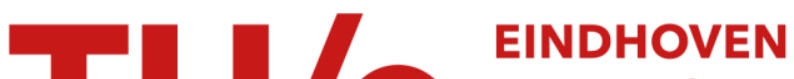 \\ UNIVERSITY OF \\ TECHNOLOGY
}

\section{Vehicle routing with stochastic time-dependent travel times}

Citation for published version (APA):

Lecluyse, C., Woensel, van, T., \& Peremans, H. (2007). Vehicle routing with stochastic time-dependent travel times. (Research paper; Vol. 2007 : 18). Universiteit van Antwerpen.

Document status and date:

Published: 01/01/2007

\section{Document Version:}

Publisher's PDF, also known as Version of Record (includes final page, issue and volume numbers)

\section{Please check the document version of this publication:}

- A submitted manuscript is the version of the article upon submission and before peer-review. There can be important differences between the submitted version and the official published version of record. People interested in the research are advised to contact the author for the final version of the publication, or visit the $\mathrm{DOI}$ to the publisher's website.

- The final author version and the galley proof are versions of the publication after peer review.

- The final published version features the final layout of the paper including the volume, issue and page numbers.

Link to publication

\section{General rights}

Copyright and moral rights for the publications made accessible in the public portal are retained by the authors and/or other copyright owners and it is a condition of accessing publications that users recognise and abide by the legal requirements associated with these rights.

- Users may download and print one copy of any publication from the public portal for the purpose of private study or research.

- You may not further distribute the material or use it for any profit-making activity or commercial gain

- You may freely distribute the URL identifying the publication in the public portal.

If the publication is distributed under the terms of Article 25fa of the Dutch Copyright Act, indicated by the "Taverne" license above, please follow below link for the End User Agreement:

www.tue.nl/taverne

Take down policy

If you believe that this document breaches copyright please contact us at:

openaccess@tue.nl

providing details and we will investigate your claim. 
DEPARTMENT OF ENVIRONMENT, TECHNOLOGY AND TECHNOLOGY MANAGEMENT

\title{
Vehicle Routing with Stochastic Time-Dependent Travel Times
}

\author{
C. Lecluyse, T. Van Woensel \& H. Peremans
}

\section{UNI VERSI TY OF ANTWERP \\ Faculty of Applied Economics \\ Stadscampus \\ Prinsstraat 13, B. 213 \\ BE-2000 Antwerpen \\ Tel. +32 (0)32204032 \\ Fax +32 (0)3 2204799 \\ http://www.ua.ac. be/tew}




\title{
FACULTY OF APPLIED ECONOMI CS
}

\author{
DEPARTMENT OF ENVIRONMENT, \\ TECHNOLOGY AND TECHNOLOGY MANAGEMENT \\ Vehicle Routing with Stochastic Time-Dependent \\ Travel Times \\ C. Lecluyse, T. Van Woensel \& H. Peremans \\ RESEARCH PAPER 2007-018 \\ SEPTEMBER 2007
}

University of Antwerp, City Campus, Prinsstraat 13, B-2000 Antwerp, Belgium Research Administration - room B.213

phone: (32) 32204032

fax: (32) 32204799

e-mail: joeri.nys@ua.ac.be

The papers can be also found at our website:

www.ua.ac.be/ tew

( research $>$ working papers)

D/ 2007/ 1169/018 


\title{
Vehicle Routing with Stochastic Time-Dependent Travel Times
}

\author{
C. Lecluyse $^{1}$, T. Van Woensel ${ }^{2}$ and H. Peremans ${ }^{1}$ \\ ${ }^{1}$ University of Antwerp, Department of Applied Economics, \\ Prinsstraat 13, 2000 Antwerp, Belgium \\ ${ }^{2}$ Eindhoven University of Technology, Den Dolech 2, Pav. E17, \\ Eindhoven NL 5600 MB, The Netherlands
}

September 26, 2007

\begin{abstract}
Assigning and scheduling vehicle routes in a stochastic time-dependent environment is a crucial management problem. The assumption that in a real-life environment everything goes according to an a priori determined static schedule is unrealistic. Our methodology builds on earlier work in which the traffic congestion is captured based on queueing theory in an analytical way and applied to the VRP problem. In this paper, we introduce the variability in the traffic flows into the model. This allows for an evaluation of the routes based on the uncertainty involved. Different experiments show that the risk taking/avoiding behaviour of the planner can be taken into account during optimization. As more weight is contributed to the variability component, the resulting optimal route will be slightly slower, but more reliable. The solution quality in terms of the $95^{\text {th }}$-percentile of the travel time distribution (assumed lognormal) will also improve.

Key words: vehicle routing, stochastic time-dependent travel times, travel time reliability
\end{abstract}

\section{Introduction}

Most traffic networks in Europe face high utilization levels, and consequently, congestion occurs. For a sufficiently high utilization, the smallest stochastic events (both in arrival processes or service processes) cause waiting, which in the case of traffic systems, materialize in lower speeds. As speeds changes, travel times vary for a given distance. As such, all transportation problems which intend to minimize total time used, are subject to these physical considerations of congestion. Consequently, the road traffic conditions and its resulting variability can not be ignored in order to carry out a good quality route optimization. Uncertainty about the traffic conditions represented in travel times is a pervasive aspect of routing and scheduling, especially in a just-in-time environment or in highly congested regions like Europe. As the cost impact due to this uncertainty can be substantial, risk sensitive planners may want to evaluate to what extent their routes and schedules are risky in terms of travel times. Indeed, a 
slightly longer route in terms of expected travel time might be more interesting for a planner if the associated variance is considerably smaller. Depending on the specific risk profile of the planner (risk averse, neutral or seeking), the resulting route could be substantially different. In this paper, the VRP problem considered deals with stochastic time-dependent travel times. In a real-life environment the travel times on an individual link are stochastic in nature. Due to weather conditions, car accidents, congestion, time and spatial fluctuations of traffic flows can be observed. The key issue considered in this paper is then the variability of the travel times which we consider to be a good approximation of travel time reliability.

This paper builds upon a number of previous papers. More specifically, we report here on the next step of research as presented in Van Woensel et al. ([42]) and Van Woensel et al. ([41]). In [41], a dynamic vehicle routing problem with time-dependent travel times due to traffic congestion was presented. The approach developed introduced the traffic congestion component modeled using a queueing approach to traffic flows. Explicitly making use of the timedependent congestion results in routes that are (considerably) shorter in terms of travel time. Additionally, it was observed that a higher number of time zones, improves the solution quality. Moreover, this effect is even magnified if one considers different road types. The authors also found that adapting the starting times for a solution has a significant effect on the obtained solution quality. Finally, [41] found that the extra calculation time needed, is significant for larger datasets but certainly worthwhile as the solution quality improved considerably. In Van Woensel et al. ([42]), both the static and the dynamic Vehicle Routing Problem (VRP) were solved using Ant Colony Optimization. Results for a large number of datasets showed that the total travel times can be improved significantly when explicitly taking into account congestion during the optimization. Moreover, a first rough expression for the variance of the travel time was obtained. Adding this expression into the objective function showed the possible advantage of considering the variance. This last observation is the starting point of the current paper on-hand. In this paper, we show how the distribution of the travel times on an individual link can be used to reduce the travel time variability. It is shown that, in addition to the mean, using the variance and the entire distribution of the travel times, better results in terms of travel time reliability are obtained.

The main contributions of the paper are:

1. Assuming a lognormal distribution for the speeds, we obtain an improved expression of the standard deviation compared to the rough expression reported in [42]. This new expression for the variance is evaluated against simulation and is shown to be a good approximation.

2. We introduce the newly obtained variability component in the objective function of our tabu search implementation. As such, we control for the degree of travel time variability during the optimization. We use this expression to optimize the VRP with time-dependent travel times taking into account the expected travel time and the standard deviation of the travel time. We show that extending the objective function with this extra information about the stochastic travel time distribution provides better results when considering the reliability of travel times. Depending 
on environmental and road conditions as well as the risk taking behavior of the planner, these improvements are substantial.

3. The reduction of the travel time variability may come at the cost of an increase of the expected travel time. To evaluate a solution, we use the $95^{t h}$ percentile of the travel time distribution as a quality measure. Using this measure, the solution quality improved, if the increase in expected travel time resulted in a lower travel time associated with the $95^{t h}$-percentile of its distribution. Results show that the reliability improves as more weight is given to the variance component during optimization. Different environmental and road conditions are compared and evaluated using this quality measure.

This paper is organized as follows: in Section 2, the literature background on our VRP variant is presented, followed by a formal description of the VRP and the objective function in Section 3. Section 4 is devoted to deriving an expression for the expected travel time and the variance of the travel times. Experimental results on solution quality are presented in Section 5. Finally, conclusions and future research are presented in Section 6.

\section{Literature review}

\section{Stochastic Vehicle Routing}

Travel times between any two customers are a stochastic process related to traffic congestion. Depending on the time of the day the traffic network will face a different level of congestion. The number of vehicles, the road capacity, road conditions, weather conditions, etc. influence the speed of the vehicles. There has been limited research on solving the VRP problem in the face of stochastic time-dependent travel times. One of the first approaches (Malandraki and Daskin [31]) treated the travel time between two customers as a function of distance and the time of the day (if this temporal component causes more travel time variation than travel time variation due to accidents, weather conditions,etc.), resulting in a piecewise constant distribution of the travel time. Although they only incorporate the temporal component of traffic density variability, they acknowledge the importance of the traffic density variability due to accidents, weather conditions and other random events. However, the FIFO principle is not necessarily satisfied (Ichoua et al. [23]).

Ichoua et al. [23] introduced a model that guarantees that if two vehicles leave the same location for the same destination (along the same path), the one that leaves first will never arrive later than the other. This is satisfied by working with step-like speed distributions and adjusting the travel speed whenever the vehicle crosses the boundary between two consecutive time periods. To reduce computational run times, they limited the number of time slices to three. The speed differences are then modeled using correction factors on the weights of the links. Donati et al. [6] extended this line of research by indicating the importance of optimizing the starting time in addition to optimizing the routes in a time-dependent environment. They show that the degree of feasibility (defined as not violating a time constraint) and optimality decreases for the 
best solutions for the constant speed model when they are used in a timedependent context with increasing variability of the traffic conditions. Similar results were also observed by Haghani and Jung [18]. In contrast with Ichoua et al. (Ichoua et al. [23]) they present the travel time as a continuous function that can accept any kind of travel time variation. In their real time approach, Haghani and Jung [18] propose to adjust the vehicle routes at certain times in the planning period to take new demands and new traffic information into account. They classify links into three types and each link type has two types of traffic flow characteristics. At any time during a day, the link travel speed is calculated based on the design speed of the link and the ratio of the travel speed to the design speed for that link type at that time. Travel times between the nodes are calculated using a time-dependent shortest path algorithm and are input to the vehicle routing problem algorithm. An important conclusion states that if the uncertainty in travel time forecasting increases, the dynamic routing strategy becomes increasingly superior. Uncertainty of travel time forecasting is inserted in 12 cases, in which they change the percentage of links that can change and the gap of that change. No information is provided on how to assess the uncertainty of the travel time forecasting.

As indicated by Ichoua et al. [23] the literature on time-dependency in a VRP context is limited. Stochastic and time-dependent travel times are more extensively operated on in shortest path analysis (e.g. Hall [19], Fu and Rilett [8], Gao and Chabini [9], [10] and He et al. [20]). He et al. [20] indicates that although mean and variance contain the most important information about path travel time, finding the single route with expected shortest travel time is not appropriate for routing of planners who are not risk neutral in their behavior. The entire travel time distribution contributes to the routing choice. Chen et al. [5] propose to using the standard deviation and the $90^{\text {th }}$ percentile travel time in addition to the mean to measure service quality.

Stochastic travel times are introduced in the vehicle routing problem by Laporte et al. [30]. Following Gendreau et al. [12] a stochastic VRP arises whenever some elements of the problem are random. A stochastic model is usually modeled in two stages. In the first stage, a planned a priori route is determined, followed by a realization of the random variables. In the second stage, a recourse or corrective action is then applied to the solution of the first stage. The cost/saving generated through the recourse may have to be considered when designing the first stage solution. Kenyon and Morton ([26]) developed two models to tackle the stochastic $V R P$ with random travel and service times with distribution assumed to be known. The first minimizes the expected completion time and the second maximizes the probability that the operation is complete before a preset target time $T$. After the routes have been constructed in the first phase, the actual travel times of those routes based on realizations of the random travel and service times are computed.

\section{Modeling Traffic}

Based on traffic counts, analytical queueing models model the behavior of traffic flows as a function of the most relevant physical and geographical determinants (i.e. free flow speed, maximum road capacity,variability due to the weather, etc.). The travel times can then be modeled much more realistically using these speeds (i.e. expressed in kilometer per hour) and are directly related to the 
physical characteristics and the geographical location on the arc.

An empirical validation of the queueing approach as well as parameter finetuning is provided in Van Woensel and Vandaele [43] and validation based on simulation results is provided in Van Woensel et al. [44]. As the distribution of the speeds is calculated based on traffic counts using queueing models in which parameters can be finetuned as to represent current environmental conditions best, the link and consequently road travel time distributions can be modeled much more realistically. More specifically, the stochastic nature of travel times is captured using queueing theory applied to traffic flows (Vandaele et al. [36]; Van Woensel [39]). By making use of this analytical approach the necessary data to model congestion (i.e. traffic flow and some queueing parameters to capture road conditions) is limited which opens the door for real-life applications.

It must be noted that several other queueing models have been proposed in the literature, all aiming at improving traffic flow modeling accuracy and flexibility (see e.g. Jain and MacGregor Smith [25], Heidemann [21]). For a detailed discussion refer to Van Woensel [39].

\section{Problem formulation}

Formally, the routing problem considered can be represented by a complete directed graph $G=(V, A)$ where $V=\{0,1, \ldots, n\}$ is a set of nodes representing the depot (0) and the customers $(1, \ldots, n)$, and $A=\{(i, j) \mid i, j \in V\}$ the set of directed links. For each customer, a fixed non-negative demand $q_{i}$ is given $\left(q_{0}=0\right)$. The aim is then to find routes with shortest travel time where the following conditions hold (Laporte [29]): Every customer is visited exactly once by exactly one vehicle; all vehicle routes start and end at the single depot every vehicle route has a total demand not exceeding the maximum vehicle capacity $Q$. Define a solution as a set $S$ with $m$ routes $R_{1}, \ldots, R_{m}$ where $R_{r}=\left(0, r_{1}, r_{2}, \ldots, 0\right)$ and each vertex $i \geq 1$ belongs to exactly one route. For the ease of notation, write $i \in R_{r}$ if the node is part of the route $R_{r}$ and write $(i, j) \in R_{r}$ if $i$ and $j$ are two consecutive nodes of $R_{r}$. $\tilde{T}_{i j}^{t_{0}}$ is defined as the stochastic travel time needed to cover the distance between $(i, j)$ leaving vertex $i$ at time $t_{0} . E\left(\tilde{T}_{i j}^{t_{0}}\right)$ and $S D\left(\tilde{T}_{i j}^{t_{0}}\right)$ are defined as the mean and standard deviation of the travel time distribution on link $(i, j)$ at starting time $t_{0}$. The basic objective function which needs to be minimized is similar to the one presented in Gendreau et al. [11] though expressed in terms of travel times:

$$
F_{1}(S)=\sum_{r=1}^{m} \sum_{(i, j) \in R_{r}} E\left(\tilde{T}_{i j}^{t_{0}}\right)+\gamma \sum_{r}\left[\sum_{i \in R_{r}} q_{i}-Q\right]^{+}
$$

where $[x]^{+}=\max (0, x)$ and $\gamma$ is a positive parameter. If the solution is feasible the second part of eq. (1) reduces to zero. On the other hand, if the solution is infeasible with respect to capacity a penalty proportional to $\gamma$ is added. Starting from this basic objective function extra variables describing the uncertainty due to variable travel times will be introduced gradually.

Indeed, only taking into account the expected travel times ignores the risk profile of the planner. Note that the proposed approach is similar to meanvariance analysis used in financial planning of portfolios ([4], [17]). In this literature, it is argued that risk can be associated with the included variance 
term (Mulvey et al. [32]). An extension of $F_{1}(S)$ thus involves adding the standard deviation $(S D)$ of the travel times, resulting in $F_{2}(S)$.

$$
F_{2}(S)=F_{1}(S)+\beta S D\left(\sum_{r} \sum_{(i, j) \in R_{r}} \tilde{T}_{i j}^{t_{0}}\right)
$$

where $\beta$ is a positive parameter. Higher risk averseness will be reflected in an increase of the parameter $\beta$ resulting in more weight attributed to the standard deviation in the objective function. The higher $\beta$, the less sensitive the solutions are to variability in the data, as such controlling the degree of travel time reliability.

\section{The travel time distribution}

In our time-dependent model, time is discretized into $P$ time zones of equal length $\triangle p$ with a different travel speed distribution associated with each time zone $p(1 \leq p \leq P)$. We first discuss the distribution of the travel times. Those speed distributions are modeled in an analytical way using queueing models. Second, an analytical expression for the expected link travel time $E\left(\tilde{T}_{i j}^{t_{0}}\right)$ is presented. Finally, we derive an expression for the variance of the travel times on a given link $\operatorname{Var}\left(\tilde{T}_{i j}^{t_{0}}\right)$, as such introducing an analytical expression for the travel time reliability.

\subsection{The distribution of travel times}

One of the earliest studies explicitly dealing with the travel speed distribution is that of Berry and Belmont [3] who looked into the distribution of the measured speed of a vehicle as it crosses a particular point on the highway. Such speed distributions were found to be normally distributed. Travel times, taken as the reciprocal of speed, are shown to be also roughly normal, although slightly skewed indicating that a lognormal distribution might be interesting as an alternative (Kharoufeh and Gautam [27]). Other empirical results (Taniguchi et al. [35] and Kwon et al. [28]) show that there is always a certain minimum time needed to cover the distance (i.e. it is impossible to traverse the distance in a time shorter than this minimum time). After this minimum, the probability increases rapidly to a maximum after which the probability slowly decreases with a long tail (i.e. skewed to the right). Due to these characteristics, Taniguchi et al. [35] proposed to use a lognormal distribution rather than a normal distribution. More recently, empirical research on the speed distribution and the resulting travel times are in line with these conclusions (Van Woensel [39]). The subsequent analysis assumes the lognormal distribution, but note that the analysis also holds for other distributions (Papoulis [33]).

\subsection{The expected travel time}

In Van Woensel et al. [42] and [41], it was shown that the expected total travel time needed to go from $i$ to $j$ starting on time $t_{0}\left(E\left(\tilde{T}_{i j}^{t_{0}}\right)\right)$ equals

$$
E\left(\tilde{T}_{i j}^{t_{0}}\right)=\varphi \triangle p+k \triangle p+\phi \triangle p
$$


with $t_{0}$ situated in the first time zone. The link travel time is thus the sum of the fraction of travel time still available in the first time zone, given by $\varphi \triangle p$ with $\varphi$ the fraction parameter $(0 \leq \varphi \leq 1)$; the duration of the $k$ intermediate time zones passed: $k \triangle p$; and the fraction of the travel time in the last time zone, given by $\phi \triangle p$, with $\phi$ the fraction parameter $(0 \leq \phi \leq 1) . k$ is implicitely defined as a random integer variable. In what follows, we propose the use of the stochastic variable $\tilde{k}_{i j}^{t_{0}}$, with $E\left(\tilde{k}_{i j}^{t_{0}}\right)$ and $k_{i j}^{t_{0}}$ the mean value respectively a random realization of the distribution of the number of time zones needed to to cover the distance between $(i, j)$ leaving vertex $i$ at time $t_{0}$. The expected travel time thus becomes

$$
E\left(\tilde{T}_{i j}^{t_{0}}\right)=E\left(\tilde{k}_{i j}^{t_{0}}\right) \triangle p
$$

In our model the starting time is a variable that needs to be optimized since it has a substantial impact on the expected travel times as periods with high congestion can be (partially) avoided (Van Woensel et al. [41]). The distance between any $i$ and $j$ is a known constant. In a time-dependent context the speed on a given link changes over time. The main point in the model is that the speed changes when the boundary between two consecutive time zones is crossed (see also Ichoua et al. [23]). The speed is a new variable that is obtained using queueing models for traffic flows. From the queueing models in Vandaele et al. [36] and Heidemann [21] it follows that the speed in any time zone can be calculated by dividing the length of the road segment $\left(1 / k_{j}\right)\left(k_{j}\right.$ is the jam density parameter) by the total time in the system $(W): s=\frac{1 / k_{j}}{W}$. The total time in the system $W$ is a function of the flow $q$. The major strength of using the queueing models, is that given the flow $q$, the speed can easily be obtained in an analytical way. The flow is a parameter that can be determined empirically, allowing to determine realistic velocity profiles as a function of time. Results showed that the developed queueing models can be used to model traffic flows quite accurately (Van Woensel and Vandaele [43]). For a more detailed discussion of the queueing models and their results, the interested reader is referred to Vandaele et al. [36] and Van Woensel et al. [40].

\subsection{The variance of the travel time}

In this section, we obtain an expression for the variance of the travel time over an entire link $\operatorname{Var}\left(\tilde{T}_{i j}^{t_{0}}\right)$. This is not trivial since every time a boundary between two time consecutive zones is crossed, not only the average speed changes, but also the entire speed distribution. Each time zone $p$ has a speed distribution $\tilde{s}_{i j}^{p}$ with different mean and variance. However, to determine the exact number of time zones needed to go from $i$ to $j$, we derive the changes in speed in the remaining time zones only from the change in speed in the first time zone. We assume that on a given link the disturbance of speed in every time zone has the same magnitude and direction as the disturbance of speed in the first time zone (e.g. if we were able to drive $10 \mathrm{~km} / \mathrm{h}$ faster than expected in the first time zone, we will be able to drive $10 \mathrm{~km} / \mathrm{h}$ faster during the entire trip). We denote this as assumption of equal absolute disturbance of speed. This assumption is valid to the extent that deviations from the mean are mainly caused by global road conditions e.g. slower speeds due to heavy rain.

A graphical representation is provided in Figure 1. The lower line represents 


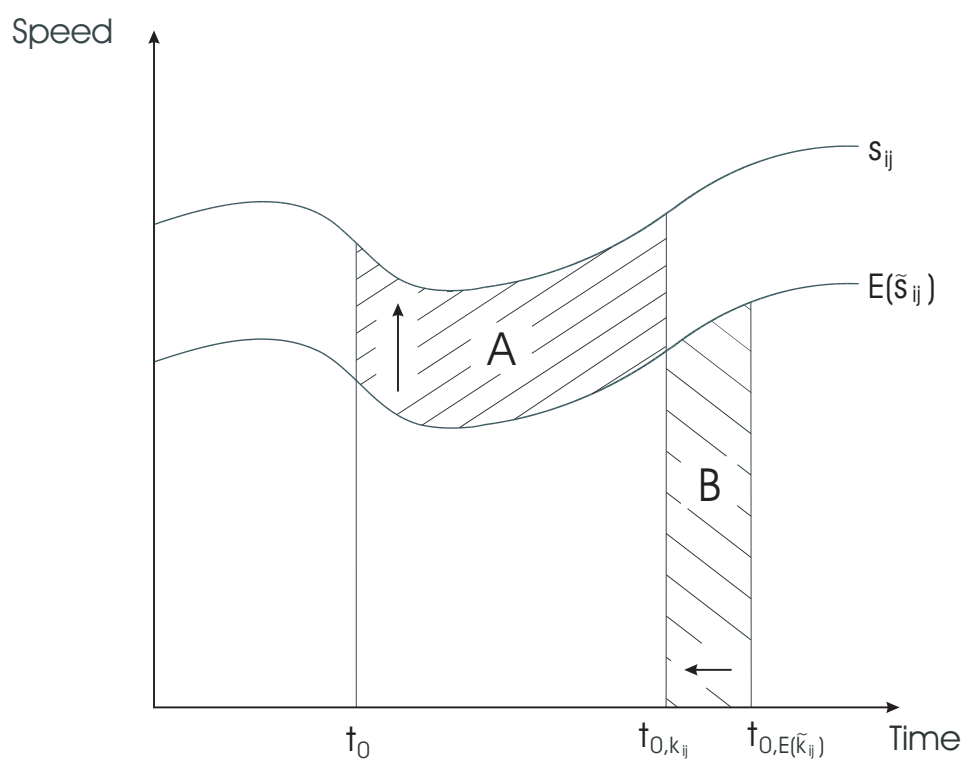

Figure 1: Under assumption of equal absolute disturbance of speeds, the new arrival time at $j$ can be determined setting $\mathrm{A}=\mathrm{B}$.

the speed distribution when driving at average speed $E\left(\tilde{s}_{i j}\right)$. Driving at those average speeds, leaving customer $i$ at time $t_{0}$, we arrive at customer $j$ at time $t_{0}+E\left(\tilde{k}_{i j}^{t_{0}}\right) \triangle p\left(=t_{0, E\left(\tilde{k}_{i j}\right)}\right)$. The stochastic variable $\tilde{k}_{i j}^{t_{0}}$ is dependent on the realization of the stochastic speed variable on that link in every time zone $\epsilon$ $\left[t_{0}, t_{0, E\left(\tilde{k}_{i j}\right)}\right]$. Under assumption of equal absolute disturbance of speed, the speed distribution will be characterized by an upward (downward) shift if the random realization of the speed in the first time zone is higher (lower) than the mean speed. In Figure 1 the situation is presented in which we are able to drive faster than expected $\left(s_{i j}^{t_{0}}>E\left(\tilde{s}_{i j}^{t_{0}}\right)\right)$. In this case, we might expect to arrive at customer $j$ at a time sooner than $t_{0, E\left(\tilde{k}_{i j}\right)}\left(\right.$ i.e. $\left.t_{0, k_{i j}}<t_{0, E\left(\tilde{k}_{i j}\right)}\right)$. Since the distance and the starting time remains the same, it now becomes possible to predict when we will arrive at customer $j$ (i.e. the cross-hatched areas in Figure 1 are identical). The difference in time zones crossed $\triangle \tilde{k}_{i j}^{t_{0}}$ (defined as $\left.k_{i j}^{t_{0}}-E\left(\tilde{k}_{i j}^{t_{0}}\right)\right)$ is thus a function of the difference in speed $\triangle \tilde{s}_{i j}^{t_{0}}$ between the realization of the speed and the mean speed $\left(s_{i j}^{t_{0}}-E\left(\tilde{s}_{i j}^{t_{0}}\right)\right)$. Formally, this yields:

$$
\triangle \tilde{k}_{i j}^{t_{0}}=\alpha \triangle \tilde{s}_{i j}^{t_{0}}
$$

where $\alpha$ is expected to have a negative sign, since an increase in speed will reduce the total time traveled. As the variance of the speed distributions will be larger, the variance of the number of times zones needed to cover the distance between the two customers will be larger and hence the variance of the link travel time.

$$
\begin{aligned}
\operatorname{Var}\left(\triangle \tilde{k}_{i j}^{t_{0}}\right) & =\operatorname{Var}\left(\alpha \triangle \tilde{s}_{i j}^{t_{0}}\right) \\
& =\alpha^{2} \operatorname{Var}\left(\triangle \tilde{s}_{i j}^{t_{0}}\right)
\end{aligned}
$$


Since $\operatorname{Var}\left(\tilde{k}_{i j}^{t_{0}}\right)=\operatorname{Var}\left(\tilde{k}_{i j}^{t_{0}}+\right.$ constant $)$, this yields:

$$
\operatorname{Var}\left(\tilde{k}_{i j}^{t_{0}}\right)=\alpha^{2} \operatorname{Var}\left(\tilde{s}_{i j}^{t_{0}}\right)
$$

From eq. (4), the variance of the travel time on a given link is as given by:

$$
\begin{aligned}
\operatorname{Var}\left(\tilde{T}_{i j}^{t_{0}}\right) & =\triangle p^{2} \operatorname{Var}\left(\tilde{k}_{i j}^{t_{0}}\right) \\
& =\triangle p^{2} \alpha^{2} \operatorname{Var}\left(\tilde{s}_{i j}^{t_{0}}\right)
\end{aligned}
$$

From Figure 1 we know that $A=B$, which allows us to derive an expression for $\alpha$

$$
\sum_{p=E\left(\tilde{k}_{i j}^{t_{0}}\right)}^{k_{i j}^{t_{0}}} E\left(\tilde{s}_{i j}^{t_{0, p}}\right) \triangle p+\sum_{p=1}^{k_{i j}^{t_{0}}} \triangle \tilde{s}_{i j}^{t_{0, p}} \triangle p=0
$$

where $\sum_{p=E\left(\tilde{k}_{i j}^{t_{0}}\right)}^{k_{i j}^{t_{0}}} E\left(\tilde{s}_{i j}^{t_{0, p}}\right) \triangle p$ can be either positive or negative. We assume $\forall p \in\left[E\left(\tilde{k}_{i j}^{t_{0}}\right), k_{i j}^{t_{0}}\right]$ that the speed is the same as the final speed. i.e. $E\left(\tilde{s}_{i j}^{t_{0, p}}\right)=$ $E\left(\tilde{s}_{i j}^{t_{0, E\left(\tilde{k}_{i j}\right)}}\right)$. The equation now reduces to:

$$
\left(k_{i j}^{t_{0}}-E\left(\tilde{k}_{i j}^{t_{0}}\right)\right) E\left(\tilde{s}_{i j}^{t_{0, E\left(\tilde{k}_{i j}\right)}}\right) \triangle p+\sum_{p=1}^{k_{i j}^{t_{0}}} \triangle \tilde{s}_{i j}^{t_{0, p}} \triangle p \simeq 0
$$

Because the distance remains unaltered, a higher speed induces a smaller amount of time to cover that distance. Evidently, the starting point remains the same. Starting from eq. (6), $\alpha$ can be calculated as follows :

$$
\left[\left(k_{i j}^{t_{0}}-E\left(\tilde{k}_{i j}^{t_{0}}\right)\right) E\left(\tilde{s}_{i j}^{t_{0, E\left(\tilde{k}_{i j}\right)}}\right)+\sum_{p=1}^{k_{i j}^{t_{0}}} \triangle \tilde{s}_{i j}^{t_{0, p}}\right] \triangle p \simeq 0
$$

Under the assumption of equal absolute disturbance of speed, it follows :

$$
\forall p \in\left[1, k_{i j}^{t_{0}}\right]: \triangle \tilde{s}_{i j}^{t_{0, p}}=\triangle \tilde{s}_{i j}^{t_{0}}
$$

This results in :

$$
\left(k_{i j}^{t_{0}}-E\left(\tilde{k}_{i j}^{t_{0}}\right)\right) E\left(\tilde{s}_{i j}^{t_{0, E\left(\tilde{k}_{i j}\right)}}\right)+k_{i j}^{t_{0}} \triangle \tilde{s}_{i j}^{t_{0}} \simeq 0
$$

Since $\triangle \tilde{k}_{i j}^{t_{0}}=k_{i j}^{t_{0}}-E\left(\tilde{k}_{i j}^{t_{0}}\right)$

$$
\triangle \tilde{k}_{i j}^{t_{0}} E\left(\tilde{s}_{i j}^{t_{0, E\left(\tilde{k}_{i j}\right)}}\right)+\left(\triangle \tilde{k}_{i j}^{t_{0}}+E\left(\tilde{k}_{i j}^{t_{0}}\right)\right) \triangle \tilde{s}_{i j}^{t_{0}} \simeq 0
$$

Solving for $\triangle \tilde{k}_{i j}^{t_{0}}$ yields :

$$
\begin{aligned}
\triangle \tilde{k}_{i j}^{t_{0}} & \simeq \frac{-E\left(\tilde{k}_{i j}^{t_{0}}\right) \triangle \tilde{s}_{i j}^{t_{0}}}{E\left(\tilde{s}_{i j}^{t_{0, E\left(\tilde{k}_{i j}\right)}}\right)+\triangle \tilde{s}_{i j}^{t_{0}}} \\
& \simeq-\frac{E\left(\tilde{k}_{i j}^{t_{0}}\right)}{s_{0, E\left(\tilde{k}_{i j}\right)}^{t_{0}}} \triangle \tilde{s}_{i j}^{t_{0}}
\end{aligned}
$$


So $\alpha$ can be written as:

$$
\alpha \simeq-\frac{E\left(\tilde{k}_{i j}^{t_{0}}\right)}{s_{i j}}
$$

As expected, $\alpha$ has a negative sign, indicating that an increase in speed will reduce the total travel time. The average number of time zones is in the nominator and the realization of the final speed in the denominator.

Recalling eq. (5), we now need to find an expression for $\operatorname{Var}\left(\tilde{s}_{i j}^{t_{0}}\right)$. Since $s=\frac{1 / k_{j}}{W}$ (Section 4.2$)$, this yields :

$$
\begin{aligned}
\operatorname{Var}\left(\tilde{s}_{i j}^{t_{0}}\right) & =\operatorname{Var}\left(\frac{1}{k_{j} \tilde{W}_{i j}^{t_{0}}}\right) \\
& =\frac{1}{\left(k_{j}\right)^{2}} \operatorname{Var}\left(\frac{1}{\tilde{W}_{i j}^{t_{0}}}\right)
\end{aligned}
$$

Starting from a lognormal distribution for $\tilde{W}_{i j}^{t_{0}}$, we can show [33] :

$$
f_{\frac{1}{\tilde{W}_{i j}}}\left(\frac{1}{\tilde{W}_{i j}^{t_{0}}}\right)=\frac{1}{\sigma \frac{1}{\tilde{W}_{i j}^{t_{0}}} \sqrt{2 \pi}} e^{-\frac{\left(\ln \left(\frac{1}{\tilde{W}_{i j}^{t_{0}}}\right)-\eta\right)^{2}}{2 \sigma^{2}}} ; \frac{1}{\tilde{W}_{i j}^{t_{0}}} \geq 0
$$

with

$$
\begin{cases}E\left(\frac{1}{\tilde{W}_{i j}^{t_{0}}}\right) & =\frac{c_{\tilde{W}_{i j}^{t_{0}}+1}^{2}}{E\left(\tilde{W}_{i j}^{t_{0}}\right)} \\ \operatorname{Var}\left(\frac{1}{\tilde{W}_{i j}^{t_{0}}}\right) & =c_{\tilde{W}_{i j}^{t_{0}}}^{2} E\left(\frac{1}{\tilde{W}_{i j}^{t_{0}}}\right)^{2} \\ c_{\frac{1}{\tilde{W}_{i j}}}^{2} & =c_{\tilde{W}_{i j}^{t_{0}}}^{2}=\frac{\operatorname{Var}\left(\tilde{W}_{i j}^{t_{0}}\right)}{\left[E\left(\tilde{W}_{i j}^{t_{0}}\right)\right]^{2}}\end{cases}
$$

Eventually determining the change in speed in the first time zone :

$$
\operatorname{Var}\left(\tilde{s}_{i j}^{t_{0}}\right)=\frac{1}{k_{j}^{2}} c_{\tilde{W}_{i j}^{t_{0}}}^{2}\left[\frac{c_{\tilde{W}_{i j}^{t_{0}}}^{2}+1}{E\left(\tilde{W}_{i j}^{t_{0}}\right)}\right]^{2}
$$

Hence using the queueing approach to traffic flow, we are able to derive a closed form approximation for the variance of the travel time as follows :

$$
\operatorname{Var}\left(\tilde{T}_{i j}^{t_{0}}\right) \simeq \frac{\triangle p^{2} \alpha^{2}}{k_{j}^{2}} c_{\tilde{W}_{i j}^{t_{j}}}^{2}\left[\frac{c_{\tilde{W}_{i j}^{t_{0}}}^{2}+1}{E\left(\tilde{W}_{i j}^{t_{0}}\right)}\right]^{2}
$$

As there is no closed expression for the variance of the waiting time, one needs to rely on approximations. These approximations have already proven their value and usability in production management (Vandaele [37]; Whitt [38]; and others). The variance of the total time in the system $\tilde{W}$, will be obtained using the two moment approximations from Whitt [38]. Whitt describes an approximation for the variance of the waiting time for the case when expected waiting time is known (either exact or approximated). The approximation has the following general form in every time zone $p: \operatorname{Var}\left(\tilde{W}^{p}\right) \simeq\left[\tilde{W}_{q}^{p}\right]^{2} c_{\tilde{W}_{q}^{p}}^{2}+c_{s}^{2} k_{j}^{2} s_{f}^{2}$, with: 
$c_{\tilde{W}_{q}^{p}}^{2}$ the squared coefficient of variation of the waiting times, $c_{s}$ the coefficient of variation of the service times and $s_{f}$ the free flow speed (see Whitt [38]).

To calculate the variance of the travel time over an entire route, it is assumed that there are no overflow effects over the different time zones, i.e. the covariance component is assumed to be zero. Therefore,

$$
\operatorname{Var}\left(\sum_{r} \sum_{(i, j) \in R_{r}} \tilde{T}_{i j}^{t_{0}}\right)=\sum_{r} \sum_{(i, j) \in R_{r}} \operatorname{Var}\left(\tilde{T}_{i j}^{t_{0}}\right)
$$

It can be shown that the convolution of $k$ lognormal distributions is again (approximative) lognormal (Beaulieu and Xie [2]). We assumed a lognormal distribution of the travel time, but the analysis could also be applied if another distribution were chosen. Simulation results in Section 5 show that the travel time distribution over an entire tour is again well approximated by a lognormal one.

\section{$5 \quad$ Experimental results}

In this section, we first described the Tabu Search implementation and the used congestion information. We then extend the objective function with the standard deviation of the travel times. Depending on the road and environmental conditions, more substantial gain in terms of travel time reliability is found by contributing more weight to this component during optimization. The decrease in variability is offset by an increase in expected travel time, therefore, we introduce the $95^{t h}$-percentile of the travel time distribution as a solution quality measure. We show that contributing more weight to the standard deviation during optimization improves the $95^{\text {th }}$-percentile of its distribution. Finally, an ARENA [24] based simulation is provided which confirms the results.

\subsection{Implementation}

In this section, a solution strategy for the VRP as described in section 2 based on local search is proposed, Aarts and Lenstra [1]. In this paper Tabu Search, first proposed by Glover ([15] and [16]), is used to generate solutions as it has a number of advantages : general applicability of the approach, flexibility for taking into account specific constraints in real cases and ease of implementation (Pirlot [34]). For this Tabu Search implementation the following references where used as a basis: Gendreau et al. [11] and [13]; Hertz et al. [22] and Van Woensel et al. [41]. The first important change made to this basic algorithm consists of replacing distance by travel time. The main change consist of extending the basic objective function with the standard deviation of the route travel time (eq. (2)). To explicitly account for the time-dependent nature of the problem, the swap neighborhood is extended to include time shifts so as to evaluate the effect of the start time on the total travel time. In case of improvement, the starting time of the associated tour is updated. The rationale behind this optimization is that a truck can decide to leave earlier or later to avoid periods of (anticipated) high congestion.

As we start from the flow on a road segment and transform it into speed, we need to explain the setting of the queueing model parameters to do so. The 
flow on a road segment is assumed given as well as the free flow speed $\left(s_{f}\right)$. The remaining queueing parameters $\left(c_{a} \in[0,1], c_{s} \in[0,1]\right.$ and $\left.k_{j}\right)$ are to be set properly. Given an empirical dataset, they can be tuned to represent the relevant environment conditions as close as possible (Van Woensel and Vandaele [43]). As this is not the objective here, we choose $c_{s}=c_{a}$ and set them both to 0.99 if we want to represent weather conditions that cause a large variability of speeds or set them to 0.75 if the weather conditions are better. The jam density $k_{j}$ will be set such that during rush hours the resulting speed is substantially lower than during off peak periods for a given observed flow $q$. As we see in Figures 2 and 3 , a $k_{j}$ of 40 for a free flow of $120 \mathrm{~km} / \mathrm{h}$ results in a reasonable speed profile as well when there is a congested flow during the entire day (Figure 2: Congested flow) or when there is only heavy congestion during the morning and evening peak hours (Figure 3: Rush-hour flow).

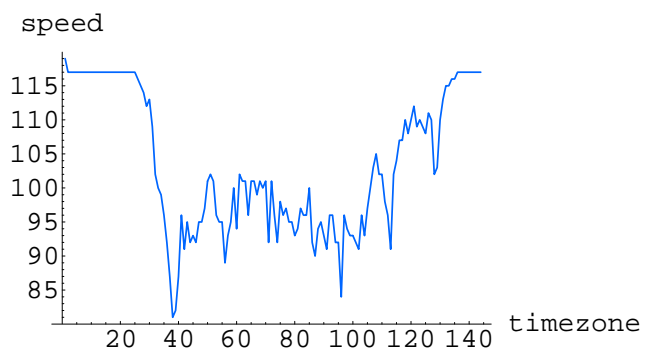

Figure 2: Speeds per time zone with $k_{j} 40$, free flow $120 \mathrm{~km} / \mathrm{h}$ and congested flows (almost) during the entire day.

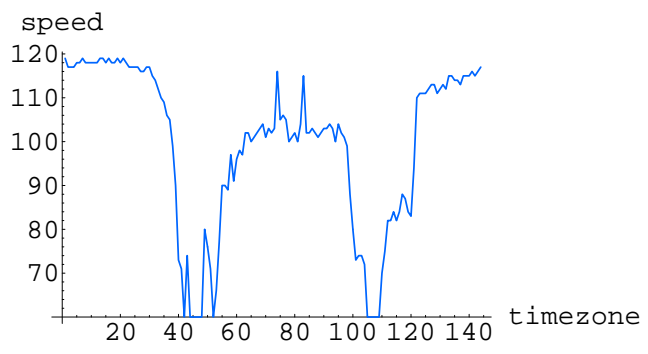

Figure 3: Speeds per time zone with $k_{j}$ 40, free flow $120 \mathrm{~km} / \mathrm{h}$ and 2 heavy congested peak hour flows.

Since the performance of Tabu Search is dependent on the quality and characteristics of the initial solution, we constructed two initial solutions to verify the robustness of the solution arrived at by our tabu search model. The initial tour is either built by going to the closest customer or by using the sweep algorithm of Gillet and Miller [14], inserting depots at the end to construct a feasible tour. 


\subsection{Including the variance in the cost function}

The values presented so far are based on expected travel times, meaning that we found a route that is on average better than another route. The underlying assumption is that the planner is risk neutral in his planning behavior, i.e. the planner does not care about the risk involved. Ignoring the associated variance of the travel time could be very costly since the variance could be unacceptably large from a managerial or planning point of view. Indeed, one might prefer to have a route that is on average slightly worse, but has a reduced variance, as such increasing the reliability of the predicted arrival times at all destinations. Depending on the risk profile a different route will be chosen. By adjusting the parameter $\beta$ in the objective function, the planner can easily insert his personal risk profile. Higher values for this parameter indicate a risk avoiding preference of the planner and will result in routes that have more reliable travel times. From Table 1 it follows that the probability that the travel time is smaller than the travel time at $T T_{\beta}$ (defined as $E(T T)+\beta S D(T T)$ ) increases as $\beta$ increases. In addition, the tail of the distribution at the right of $T T_{\beta}$ also contributes to the total mass of the distribution. The higher $\beta$, the less mass there is left that contributes to the total mass of the distribution. For instance, for dataset $32 \mathrm{k} 5$ from Augerat, the optimal route has a travel time distribution with $\sigma$ (scale parameter of the lognormal travel time distribution) $=0.376$. When $\beta=2.0$, $95.73 \%$ of the population of travel times is below $T T_{\beta}$. The remaining $4.27 \%$ however still contributes $8.93 \%$ of the total mass (Finkel [7]). Therefore, we will examine $\beta$-values up to 3.0, where the remaining mass is about $3 \%$ for this set.

\begin{tabular}{lrrrrrrc}
\hline$\beta$ & $\beta=0.0$ & $\beta=0.5$ & $\beta=1.0$ & $\beta=1.5$ & $\beta=2.0$ & $\beta=2.5$ & $\beta=3.0$ \\
\hline$p\left(T T<T T_{\beta}\right)(\%)$ & 57.45 & 74.58 & 85.61 & 92.11 & 95.73 & 97.71 & 98.77 \\
$\operatorname{mass}\left(T T>T T_{\beta}\right)(\%)$ & 57.45 & 38.76 & 24.59 & 15.00 & 8.93 & 5.25 & 3.06 \\
\hline
\end{tabular}

Table 1: Probability for $T T<T T_{\beta}$ and associated remaining mass in the tail of the travel time distribution for different $\beta$-values when $\sigma$ (scale parameter of the lognormal travel time distribution) $=0.376$.

The values in Table 2 indicate the relative decline of the standard deviation of the total travel time of the newly constructed route (with associated $\beta$ ) compared to the standard deviation of the travel time found by a minimization with $\beta=0$. The values are an average over all datasets (the detailed tables are included in Appendix A). For instance, the standard deviation of the total travel time reduces with $3.30 \%$ on average over all datasets when the flow is congested during the entire day, $c_{a}=0.99$ and setting $\beta=0.5$. As the weight to the standard deviation of the travel time adopts higher values, the standard deviation of the associated best route continues to decrease, regardless of the environmental and road conditions. The best improvement however is obtained by increasing the value of $\beta$ from 0 to 0.5 , whereas the additional improvement of further steps reduces in magnitude. It is thus crucially important to include the variability of the travel times in the objective function. Better improvements will be expected when the road conditions are bad $\left(c_{a}=0.99\right)$. If road conditions are bad, the speed will fluctuate more, which makes it more difficult to predict when we will complete a tour as opposed to better road conditions. By introducing this uncertainty factor in objective function, better improvement 
will be expected when road conditions are bad. If the flow is congested during the entire day, the improvement is also more substantial as compared to a flow which is characterized by two rush-hours. This is due to the fact that between the two congestion periods, drivers are able to uphold free flow speed, which evidently is associated with less variability.

\begin{tabular}{lrrrrrr}
\hline Test situation & $\beta=0.5$ & $\beta=1.0$ & $\beta=1.5$ & $\beta=2.0$ & $\beta=2.5$ & $\beta=3.0$ \\
\hline congested flow, $c_{a}=0.99$ & -3.30 & -4.18 & -4.72 & -5.17 & -5.40 & -5.56 \\
congested flow, $c_{a}=0.75$ & -1.61 & -2.18 & -2.52 & -2.75 & -3.14 & -3.47 \\
rush-hour flow, $c_{a}=0.99$ & -3.17 & -3.83 & -4.20 & -4.55 & -4.71 & -5.04 \\
rush-hour flow, $c_{a}=0.75$ & -1.45 & -2.05 & -2.50 & -2.95 & -3.32 & -3.46 \\
\hline
\end{tabular}

Table 2: Impact of $\beta$ on reduction of the standard deviation (\%) when comparing to the standard deviation of the travel time with $\beta=0$.

In Van Woensel et al. [41] it has been shown that for the VRP with timedependent travel times modeled using queueing theory, the extra computational effort due to the increased amount of information in eq. (1) is significant, but certainly worthwhile. The computational effort to extend the objective function with the standard deviation of the travel times is of the same magnitude of the computational effort without this extra information. Of course, the standard deviation of the travel times has always been calculated, but when $\beta=0$ it is not used during optimization. It has been calculated to provide the planner with an indication of how risky his route with shortest expected total travel time is. Computation times range between 60 and 2000 seconds. The computational effort is not a function of $\beta$, but is related to the size of the set. The starting solution for each new $\beta$ value is the best solution from the previous $\beta$ value. The rationale behind it is that the planner most likely will be interested in the route with shortest expected travel time. If the associated standard deviation is too large from his managerial point of view, he then could start from this solution to optimize it in terms of standard deviation as well.

\subsection{The $95^{\text {th }}$-percentile as a quality measure}

The reduction of the standard deviation comes at a certain cost, i.e. a likely increase of the average travel time. To check whether this cost is acceptable, we propose the use of the $95^{t h}$-percentile as a quality measure assuming a lognormal distribution for the travel time. The $95^{\text {th }}$-percentile combines the expected total travel time and variance of total travel time into a single number. Figure 4 illustrates that if the $95^{\text {th }}$-percentile of the solution with worse average travel time, but better standard deviation (Distribution 2) is lower than the one with best average travel time (Distribution 1), we have nevertheless managed to improve solution quality. Indeed, this would mean that in $95 \%$ of all cases solution 2 would result in a shorter total travel time than solution 1.

This can also be derived from our test cases. The impact of $\beta$ on the improvement in the $95^{t h}$-percentile can be observed in Table 3 . The travel time associated with the $95^{t h}$-percentile decreases when more weight (higher $\beta$ ) is given to the standard deviation in the objective function. The best improvement is observed in the first step, regardless of the test situation. The additional improvement of higher $\beta$ values reduces in magnitude. This means that although 


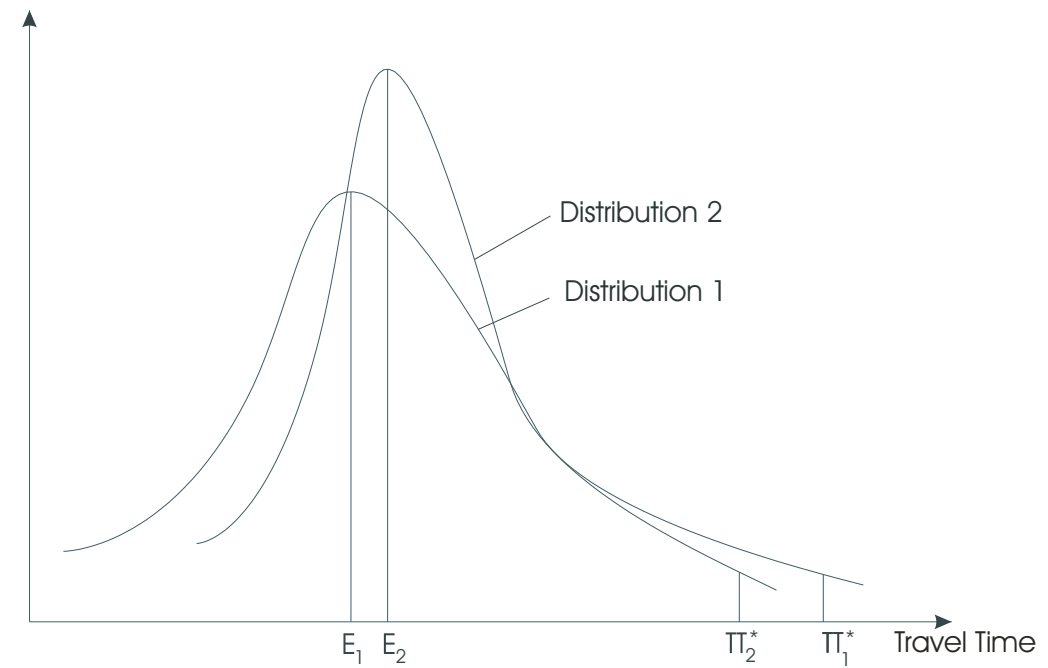

Figure 4: Impact of $95^{t h}$-percentile on solution quality (Lognormal distribution)

the average travel time will become larger with increasing $\beta$, the total travel time will be better in $95 \%$ of all cases but with decreasing importance. If the road condition are good (low $c_{a}$ ), the relative improvement of the travel time of the $95^{t h}$-percentile is more substantial for the congested flow throughout the day compared to a flow with two rush-hours for equal $\beta$ values. On the other hand, if road conditions are bad, the best relative improvement are observed for the two rush-hour flow. The variance of the travel time will be larger if the flow is congested throughout the day compared to the 2 rush-hour flow. Indeed, if we recall eq. (9) a larger variance of the travel time will be observed when more time zones are crossed (due to lower speed) or when $\alpha$ is high (higher average number of time zones crossed and lower speed). As the variance of the travel time will be larger for the congested flow, allowing some weight to this component will result in solutions where the relative improvement will be more substantial compared to the 2 rush-hour flow. From Table 4 we see that squared coefficient of variation of the travel times is higher for the congested flow, regardless of the road conditions. This conclusion is in line with what can be expected from a theoretical point of view. Furthermore, if weather conditions are good, the squared coefficient of the travel times of the two flow types are of the same magnitude. Therefore, since the standard deviation of the travel times of the congested flow is higher for the congested flow, better improvements can be expected for this flow type with increasing $\beta$. The squared coefficient of the travel times for the flow with two rush-hours is larger than the congested flow. This means that for the flow with two rush-hours the standard deviation is relatively large compared to the mean. Adding some weight to it will thus result in better relative better results.

In Table 5, the gain in travel time (in minutes) of the $95^{\text {th }}$-percentile is presented in minutes for the test cases when comparing $\beta=3$ with $\beta=0$. For instance, the gain over all Augerat sets for the congested flow with $c_{a}=0.99$ is on average 88.32 minutes. The minimum improvement for that test situation is 15.58 minutes and the maximum improvement is almost 3 hours (166.32 min- 


\begin{tabular}{lcccccc}
\hline Test situation & $\beta=0.5$ & $\beta=1.0$ & $\beta=1.5$ & $\beta=2.0$ & $\beta=2.5$ & $\beta=3.0$ \\
\hline congested flow, $c_{a}=0.99$ & -1.32 & -1.62 & -1.75 & -1.94 & -1.97 & -1.99 \\
congested flow, $c_{a}=0.75$ & -0.62 & -0.82 & -0.94 & -0.98 & -1.12 & -1.16 \\
rush-hour flow, $c_{a}=0.99$ & -1.38 & -1.66 & -1.79 & -1.90 & -1.99 & -2.07 \\
rush-hour flow, $c_{a}=0.75$ & -0.52 & -0.72 & -0.84 & -0.91 & -1.06 & -1.07 \\
\hline
\end{tabular}

Table 3: Impact of $\beta$ on improvement of the $95^{\text {th }}$-percentile (\%) when comparing the $95^{t h}$-percentile with $\beta=0$ (lognormal distribution).

\begin{tabular}{lrrrrrrr}
\hline Test situation & $\beta=0.0$ & $\beta=0.5$ & $\beta=1.0$ & $\beta=1.5$ & $\beta=2.0$ & $\beta=2.5$ & $\beta=3.0$ \\
\hline congested flow, $c_{a}=0.99$ & 0.110 & 0.103 & 0.101 & 0.100 & 0.099 & 0.098 & 0.098 \\
congested flow, $c_{a}=0.75$ & 0.038 & 0.037 & 0.037 & 0.036 & 0.036 & 0.036 & 0.036 \\
rush-hour flow, $c_{a}=0.99$ & 0.113 & 0.106 & 0.104 & 0.103 & 0.102 & 0.102 & 0.101 \\
rush-hour flow, $c_{a}=0.75$ & 0.038 & 0.037 & 0.037 & 0.036 & 0.036 & 0.036 & 0.036 \\
\hline
\end{tabular}

Table 4: Squared coefficient of variation of the travel times for given test situation and $\beta$ values.

utes). It is clear that the reduction of the standard deviation of the travel time is substantial enough to overcome the increase in average travel time. Extending the objective function to account for the travel time variability provides results with better overall reliability, especially when road conditions are bad (high $c_{a}$ ). More detailed results for a congested flow with $c_{a}=0.99$ can be found in Table A.1.

\begin{tabular}{lccc}
\hline Test situation & Average & Minimum & Maximum \\
\hline congested flow, $c_{a}=0.99$ & 88.32 & 15.58 & 166.32 \\
congested flow, $c_{a}=0.75$ & 35.11 & 6.90 & 93.57 \\
rush-hour flow, $c_{a}=0.99$ & 81.61 & 15.85 & 259.98 \\
rush-hour flow, $c_{a}=0.75$ & 32.26 & 0.33 & 68.10 \\
\hline
\end{tabular}

Table 5: Improvement (in minutes) of the $95^{\text {th }}$-percentile of the tour travel time when comparing the optimal routes with $\beta=3$ and $\beta=0$.

\subsection{Simulation results}

To validate the approximations used when building the variance estimating model presented above, we constructed a simulation in ARENA [24] in which we reconstructed the route as a sequence of lognormal distributions (representing the links) with mean and standard deviation as obtained through queueing theory (see section 4). For set 32k5, 3001 trucks completed the tour and their travel times have been plotted in Figure 5. Results indicate that the resulting tour travel time is indeed lognormally distributed (there clearly is a long tail to the right). In addition, the plotted results are close to the theoretical tour travel time distribution. The travel time associated with the $95^{t h}$-percentile is 2205.5 minutes (Figure 5, Table 6), which corresponds with what we expect from the theoretic travel time distribution (2262.71 minutes, based on Table A.2.

The positive impact in terms of travel time reliability of optimizing the $V R P$ when allowing more weight to the standard deviation is approved by the 


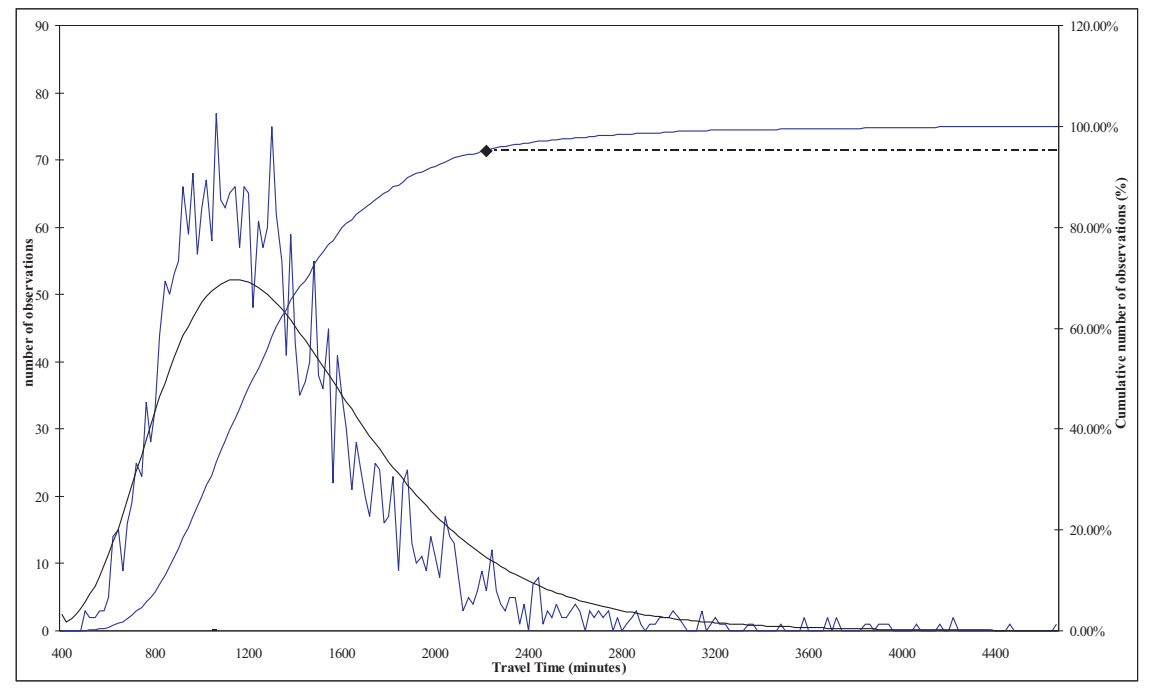

Figure 5: Travel time distributions of set $32 k 5$ with congested flow and $c_{a}=0.99$. Results following a simulation with ARENA are plotted together with the expected lognormal distribution (parameters derived from Tabu Search solution).

simulation results provided in Table 6 . The best solutions of a Tabu Search optimization with $\beta$-values $\in\{0 . ; 3.0\}$ are reconstructed in ARENA. For each set the average travel time increases and the standard deviation of the travel time decreases, this way increasing the travel time reliability. The decrease in the standard deviation is substantial enough to improve the solution quality (better travel time associated with the $95^{\text {th }}$-percentile). $\beta$-values $\in\{0 . ; 3.0\}$ are two extreme situations. The planner can use any value in between regarding his own risk avoiding behavior. From a planning point of view, it is better to have more predictability in the routing than a potentially faster route. The uncertainty about that eventual arrival time will be avoided as the planner wishes to plan as close to reality as possible.

\begin{tabular}{llccc}
\hline & & Average TT & Standard Deviation TT & $95^{\text {th }}$-percentile TT \\
\hline $32 \mathrm{k} 5$ & $\beta=0.0$ & 1320.87 & 550.77 & 2205.5 \\
& $\beta=3.0$ & 1332.51 & 514.51 & 2169.5 \\
\hline $38 \mathrm{k} 5$ & $\beta=0.0$ & 1286.60 & 480.72 & 2087.7 \\
& $\beta=3.0$ & 1296.14 & 471.02 & 2049.4 \\
\hline \multirow{2}{*}{$80 \mathrm{k} 10$} & $\beta=0.0$ & 2701.11 & 746.35 & 4007.0 \\
& $\beta=3.0$ & 2720.64 & 685.73 & 3972.9 \\
\hline
\end{tabular}

Table 6: Comparing the best routes (through Tabu Search optimization with respective $\beta$-values) for three sets in congested flow with $c_{a}=0.99$ using ARENA. Average travel time, standard deviation of the travel time and $95^{\text {th }}$-percentile are provided after 3001 trucks completed the best routes. 


\section{Conclusions and future research}

The capability of taking into account time-dependent travel speeds is extremely valuable, not only because speed profiles do affect the objective function of the optimization, but also, as demonstrated above, the best solutions for the time-independent problem applied in a time-dependent context, are in general suboptimal. Minimizing the expected travel time however still does not deal with the true stochastic nature of the travel times. As the real speed is a realization of a stochatic process, it is equally important to account for the variability of the speed and thus the travel time uncertainty when planning a route. This paper aims at obtaining a routing solution that performs well in the face of the extra complications due to congestion, which eventually leads to a better solution, i.e. more reliable routes in terms of travel time. These more realistic solutions have the potential to reduce real operating costs for a broad range of industries which daily face routing problems.

Applying queueing theory to the $V R P$-problem allows for an analytical way to obtain the average speeds and the variance of the speeds in every time zone on every link. The queueing parameters can be tuned as to represent the current road and environmental conditions best. Starting from these speed distributions, the variance of the travel time can easily be obtained and accounted for during optimization. When including the variance of the travel time, the potential applications are vast: it gives a manager a powerful tool to incorporate and take into account congestion uncertainty in his optimization. The higher the risk averseness of the planner, the more weight is allowed to that factor while optimizing, as such making the resulting routes more reliable and predictable. Although the gain in terms of less variability will be offset by a higher average travel time, the travel time associated with $95^{\text {th }}$-percentile will improve. Results and simulation results confirm with these conclusions. Depending on the road and environmental conditions, this improvement will be more or less substantial. The more the planner desires routes with less variability, the less time and effort needs to be invested in replanning (in real-time) during the day.

Due to the analytical approach to congestion, the developed approach can be extended to $V R P$ with (soft or hard) time windows. Hence, combined with the risk profile discussed above, the manager has a powerful tool not only for planning and scheduling his vehicle fleet, but on top of that he will be able to use the model for adequately determining costs and setting his rates at the individual customer level (e.g. someone with a tight and hard time window will need to pay more than a customer which is highly flexible in his requirements). The approach also opens doors for real life simulations in which actual flows and environment variables can help to determine a better travel time in terms of average travel time as well as more predictable arrival times. 


\section{Appendix A}

\begin{tabular}{lccc}
\hline set & $T T_{95^{t h}}$ with $\beta=0.0$ & $T T_{95^{\text {th }}}$ with $\beta=3.0$ & difference per tour \\
\hline $32 \mathrm{k} 5$ & 2837.73 & 2764.45 & 73.28 \\
$33 \mathrm{k} 5$ & 2401.07 & 2372.50 & 28.57 \\
$33 \mathrm{k} 6$ & 2750.17 & 2734.59 & 15.58 \\
$34 \mathrm{k} 5$ & 2754.68 & 2716.03 & 38.65 \\
$36 \mathrm{k} 5$ & 2937.06 & 2851.35 & 85.71 \\
$37 \mathrm{k} 5$ & 2361.80 & 2340.49 & 21.31 \\
$37 \mathrm{k} 6$ & 3441.23 & 3348.28 & 92.95 \\
$38 \mathrm{k} 5$ & 2652.30 & 2581.25 & 71.05 \\
$39 \mathrm{k} 5$ & 2919.02 & 2798.12 & 120.90 \\
$39 \mathrm{k} 6$ & 2871.41 & 2797.08 & 74.33 \\
$44 \mathrm{k} 6$ & 3170.43 & 3075.96 & 94.47 \\
$45 \mathrm{k} 6$ & 3110.56 & 3043.42 & 67.14 \\
$45 \mathrm{k} 7$ & 3737.10 & 3641.49 & 95.61 \\
$46 \mathrm{k} 7$ & 3083.80 & 3026.86 & 56.94 \\
$48 \mathrm{k} 7$ & 3463.91 & 3357.77 & 106.14 \\
$53 \mathrm{k} 7$ & 3299.89 & 3217.75 & 82.14 \\
$54 \mathrm{k} 7$ & 3659.22 & 3501.76 & 157.46 \\
$55 \mathrm{k} 9$ & 3627.42 & 3551.77 & 75.65 \\
$60 \mathrm{k} 9$ & 4138.39 & 4018.08 & 120.31 \\
$61 \mathrm{k} 9$ & 3231.38 & 3129.59 & 101.79 \\
$62 \mathrm{k} 8$ & 3957.55 & 3791.23 & 166.32 \\
$63 \mathrm{k} 9$ & 4770.79 & 4657.88 & 112.91 \\
$63 \mathrm{k} 10$ & 4107.71 & 3942.50 & 165.21 \\
$64 \mathrm{k} 9$ & 4171.21 & 4089.23 & 81.98 \\
$65 \mathrm{k} 9$ & 3762.25 & 3620.65 & 141.60 \\
$69 \mathrm{k} 9$ & 3538.78 & 3477.97 & 60.81 \\
$80 \mathrm{k} 10$ & 4848.35 & 4772.63 & 75.72 \\
\hline
\end{tabular}

Table A.1: Improvement (in minutes) of the $95^{\text {th }}$-percentile of the tour travel time $\left(T T_{95^{t h}}\right)$ when comparing $\beta=3$ with $\beta=0$ in congested flow with $c_{a}=0.99$. 


\begin{tabular}{|c|c|c|c|c|c|c|c|c|c|c|c|c|c|c|}
\hline set & & $=0.0$ & & $=0.5$ & & $=1.0$ & & $=1.5$ & & $=2.0$ & & $=2.5$ & & 3.0 \\
\hline & $\mathrm{E}(\mathrm{TT})$ & $\mathrm{SD}(\mathrm{TT})$ & $\mathrm{E}(\mathrm{TT})$ & $\mathrm{SD}(\mathrm{TT})$ & $\mathrm{E}(\mathrm{TT})$ & $\mathrm{SD}(\mathrm{TT})$ & $\mathrm{E}(\mathrm{TT})$ & $\mathrm{SD}(\mathrm{TT})$ & $\mathrm{E}(\mathrm{TT})$ & $\mathrm{SD}(\mathrm{TT})$ & $\mathrm{E}(\mathrm{TT})$ & $\mathrm{SD}(\mathrm{TT})$ & $\mathrm{E}(\mathrm{TT})$ & $\mathrm{SD}(\mathrm{TT})$ \\
\hline $32 \mathrm{k} 5$ & 1308.87 & 509.62 & 1309.75 & 494.81 & 1309.75 & 494.81 & 1309.75 & 494.81 & 1309.75 & 494.81 & 1309.75 & 494.81 & 1315.24 & 483.07 \\
\hline $33 \mathrm{k} 5$ & 1130.72 & 423.45 & 1130.97 & 416.24 & 1130.97 & 416.24 & 1137.49 & 411.67 & 1137.49 & 411.67 & 1137.49 & 411.67 & 1137.49 & 411.67 \\
\hline $33 \mathrm{k} 6$ & 1289.95 & 486.74 & 1290.37 & 484.89 & 1290.82 & 484.31 & 1290.82 & 484.31 & 1290.82 & 484.31 & 1298.22 & 478.79 & 1298.22 & 478.79 \\
\hline $34 \mathrm{k} 5$ & 1301.00 & 484.56 & 1302.55 & 471.16 & 1302.55 & 471.16 & 1302.55 & 471.16 & 1302.55 & 471.16 & 1302.55 & 471.16 & 1302.55 & 471.16 \\
\hline $36 \mathrm{k} 5$ & 1376.40 & 520.22 & 1378.06 & 511.64 & 1385.02 & 489.03 & 1385.02 & 489.03 & 1387.35 & 488.00 & 1387.35 & 488.00 & 1387.35 & 488.00 \\
\hline $37 \mathrm{k} 5$ & 1169.69 & 397.37 & 1170.40 & 390.20 & 1170.40 & 390.03 & 1170.40 & 390.03 & 1170.40 & 390.03 & 1170.40 & 390.03 & 1170.40 & 390.03 \\
\hline 37 k6 & 1612.01 & 609.74 & 1612.01 & 609.74 & 1621.54 & 576.56 & 1624.45 & 574.61 & 1624.45 & 574.61 & 1624.45 & 574.61 & 1624.45 & 574.61 \\
\hline $38 \mathrm{k} 5$ & 1275.30 & 459.00 & 1281.84 & 443.75 & 1281.84 & 443.75 & 1281.84 & 443.75 & 1284.35 & 432.30 & 1284.35 & 432.30 & 1284.35 & 432.30 \\
\hline $39 \mathrm{k} 5$ & 1412.75 & 502.09 & 1398.51 & 469.07 & 1404.66 & 465.00 & 1404.92 & 464.40 & 1404.92 & 464.40 & 1404.92 & 464.40 & 1404.92 & 464.40 \\
\hline $39 \mathrm{k} 6$ & 1399.79 & 490.54 & 1402.07 & 482.39 & 1404.30 & 464.26 & 1404.30 & 464.26 & 1404.30 & 464.26 & 1404.30 & 464.26 & 1404.30 & 464.26 \\
\hline $44 \mathrm{k} 6$ & 1618.05 & 517.46 & 1602.69 & 494.44 & 1605.05 & 491.10 & 1605.05 & 491.10 & 1605.05 & 491.10 & 1617.00 & 486.32 & 1617.00 & 486.32 \\
\hline $45 \mathrm{k} 6$ & 1577.59 & 510.99 & 1582.81 & 486.54 & 1582.81 & 486.54 & 1582.81 & 486.54 & 1582.81 & 486.54 & 1593.91 & 483.17 & 1593.91 & 483.17 \\
\hline $45 \mathrm{k} 7$ & 1850.73 & 628.79 & 1853.36 & 613.18 & 1853.36 & 613.18 & 1843.76 & 612.70 & 1853.10 & 597.36 & 1853.10 & 597.36 & 1862.01 & 593.16 \\
\hline $46 \mathrm{k} 7$ & 1575.34 & 502.82 & 1575.19 & 493.59 & 1575.19 & 493.59 & 1575.21 & 490.11 & 1585.51 & 480.45 & 1585.51 & 480.45 & 1585.51 & 480.45 \\
\hline $48 \mathrm{k} 7$ & 1759.79 & 568.04 & 1761.24 & 546.72 & 1761.24 & 546.72 & 1771.48 & 534.62 & 1766.99 & 530.26 & 1766.99 & 530.26 & 1766.99 & 530.26 \\
\hline $53 \mathrm{k} 7$ & 1723.51 & 525.46 & 1726.75 & 505.38 & 1731.80 & 500.54 & 1731.80 & 500.54 & 1730.17 & 495.86 & 1730.17 & 495.86 & 1730.17 & 495.86 \\
\hline $54 \mathrm{k} 7$ & 1852.56 & 602.22 & 1847.29 & 551.49 & 1847.29 & 551.49 & 1847.29 & 551.49 & 1847.29 & 551.49 & 1847.29 & 551.49 & 1847.29 & 551.49 \\
\hline $55 \mathrm{k} 9$ & 1814.46 & 604.32 & 1817.64 & 583.56 & 1817.77 & 582.98 & 1824.49 & 575.76 & 1824.49 & 575.76 & 1824.49 & 575.76 & 1824.49 & 575.76 \\
\hline $60 \mathrm{k} 9$ & 2109.13 & 676.42 & 2106.68 & 672.93 & 2122.05 & 640.41 & 2126.92 & 631.44 & 2125.05 & 631.01 & 2125.05 & 631.01 & 2125.05 & 631.01 \\
\hline $61 \mathrm{k} 9$ & 1738.52 & 497.62 & 1745.23 & 474.12 & 1745.33 & 473.49 & 1742.62 & 466.12 & 1735.04 & 464.85 & 1735.04 & 464.85 & 1735.04 & 464.85 \\
\hline $62 \mathrm{k} 8$ & 2075.32 & 627.41 & 2066.55 & 587.70 & 2069.36 & 575.17 & 2069.36 & 575.17 & 2070.49 & 574.26 & 2070.49 & 574.26 & 2081.65 & 569.86 \\
\hline $63 \mathrm{k} 9$ & 2487.97 & & 2490.91 & 724.25 & 2490.91 & 724.25 & & 721.00 & 2494.88 & 721.00 & 2494.88 & 721.00 & 2494.88 & 721.00 \\
\hline $63 \mathrm{k} 1$ & 2148.47 & 653.08 & 2152.90 & 620.42 & 2152.90 & 620.42 & 157.79 & 614.21 & 2154.51 & 602.37 & 2140.52 & 600.66 & 2140.52 & 600.66 \\
\hline $64 \mathrm{k} 9$ & 2203.39 & 655.94 & 2194.94 & 642.94 & 5.86 & 641.34 & 208.12 & 633.27 & 2208.12 & 633.27 & 2225.64 & 621.17 & 2226.71 & 620.84 \\
\hline $65 \mathrm{k} 9$ & 1980.67 & 593.86 & 1983.10 & 556.15 & 1983.10 & 556.15 & 1993.41 & 546.94 & 1976.04 & & 1987.30 & 544.45 & 1987.30 & 544.45 \\
\hline $69 \mathrm{k} 9$ & 1969.75 & 523.01 & 1969.91 & 513.82 & 1973.78 & 511.20 & 1979.24 & 505.53 & 1975.15 & 500 & 1975.15 & 500.94 & 1975.15 & 500.94 \\
\hline $80 \mathrm{k} 10$ & 2678.84 & 723.17 & 2675.01 & 709.02 & 2675.01 & 709.02 & 2682.69 & 702.65 & 2690.65 & 699.26 & 2687.41 & 694.83 & 2702.42 & 690.07 \\
\hline
\end{tabular}

Table A.2: Impact of increasing $\beta$-values when there is congestion during the entire day and when the weather conditions are bad. 


\begin{tabular}{|c|c|c|c|c|c|c|c|c|c|c|c|c|c|c|}
\hline set & & $=0.0$ & & $=0.5$ & & $=1.0$ & & $=1.5$ & & $=2.0$ & & $=2.5$ & & 3.0 \\
\hline & $\mathrm{E}(\mathrm{TT})$ & $\mathrm{SD}(\mathrm{TT})$ & $\mathrm{E}(\mathrm{TT})$ & $\mathrm{SD}(\mathrm{TT})$ & $\mathrm{E}(\mathrm{TT})$ & $\mathrm{SD}(\mathrm{TT})$ & $\mathrm{E}(\mathrm{TT})$ & $\mathrm{SD}(\mathrm{TT})$ & $\mathrm{E}(\mathrm{TT})$ & $\mathrm{SD}(\mathrm{TT})$ & $\mathrm{E}(\mathrm{TT})$ & $\mathrm{SD}(\mathrm{TT})$ & $\mathrm{E}(\mathrm{TT})$ & $\mathrm{SD}(\mathrm{TT})$ \\
\hline $32 \mathrm{k} 5$ & 1135.53 & 268.68 & 1138.78 & 255.37 & 1138.78 & 255.37 & 1138.78 & 255.37 & 1138.78 & 255.37 & 1138.78 & 255.37 & 1138.78 & 255.37 \\
\hline $33 \mathrm{k} 5$ & 971.26 & 210.93 & 971.54 & 209.14 & 971.54 & 209.14 & 971.88 & 208.42 & 971.88 & 208.42 & 971.88 & 208.42 & 971.88 & 208.42 \\
\hline $33 \mathrm{k} 6$ & 1095.39 & 246.57 & 1096.01 & 244.95 & 1096.01 & 244.95 & 1096.01 & 244.95 & 1096.45 & 244.87 & 1097.41 & 243.21 & 1097.41 & 243.21 \\
\hline $34 \mathrm{k} 5$ & 1145.11 & 249.06 & 1115.37 & 244.54 & 1115.37 & 244.54 & 1115.75 & 244.49 & 1115.75 & 244.49 & 1115.75 & 244.49 & 1117.20 & 243.62 \\
\hline $36 \mathrm{k} 5$ & 1212.13 & 276.10 & 1208.73 & 271.54 & 1205.68 & 257.85 & 1206.13 & 257.54 & 1206.13 & 257.54 & 1206.13 & 257.54 & 1206.13 & 257.54 \\
\hline $37 \mathrm{k} 5$ & 1017.22 & 208.43 & 1013.11 & 206.74 & 1011.91 & 206.49 & 1011.91 & 206.49 & 1013.97 & 204.85 & 1014.90 & 204.07 & 1014.90 & 204.07 \\
\hline $37 \mathrm{k} 6$ & 1399.09 & 316.62 & 1399.94 & 312.14 & 1400.19 & 312.34 & 1400.90 & 311.65 & 1402.60 & 309.10 & 1381.35 & 297.46 & 1378.32 & 295.87 \\
\hline $38 \mathrm{k} 5$ & 1097.30 & 231.06 & 1094.87 & 227.70 & 1094.87 & 227.70 & 1097.40 & 225.38 & 1097.40 & 225.38 & 1097.44 & 220.56 & 1097.44 & 220.56 \\
\hline $39 \mathrm{k} 5$ & 1211.69 & 252.98 & 1211.90 & 249.71 & 1212.81 & 248.17 & 1214.29 & 247.03 & 1214.29 & 247.03 & 1214.29 & 247.03 & 1214.29 & 247.03 \\
\hline $39 \mathrm{k} 6$ & 1202.06 & 245.04 & 1201.99 & 243.88 & 1203.24 & 241.53 & 1205.50 & 239.64 & 1205.50 & 239.64 & 1208.37 & 238.35 & 1208.37 & 238.35 \\
\hline $44 \mathrm{k} 6$ & 1392.41 & 261.12 & 1392.46 & 259.33 & 1391.82 & 261.02 & 1393.98 & 256.77 & 1387.14 & 258.41 & 1388.23 & 255.38 & 1388.23 & 255.38 \\
\hline $45 \mathrm{k} 6$ & 1343.82 & 254.55 & 1343.85 & 253.55 & 1344.54 & 253.04 & 1344.54 & 253.04 & 1353.25 & 247.11 & 1353.25 & 247.11 & 1353.25 & 247.11 \\
\hline $45 \mathrm{k} 7$ & 1593.02 & 322.71 & 1583.00 & 307.09 & 1583.00 & 307.09 & 1568.16 & 300.47 & 1571.94 & 298.65 & 1571.94 & 298.65 & 1571.97 & 298.54 \\
\hline $46 \mathrm{k} 7$ & 1358.84 & 258.39 & 1358.91 & 258.16 & 1353.02 & 256.98 & 1353.47 & 256.17 & 1353.47 & 256.17 & 1355.75 & 254.07 & 1355.75 & 254.07 \\
\hline $48 \mathrm{k} 7$ & 1517.21 & 287.02 & 1517.86 & 278.71 & 517.86 & 278.71 & 517.86 & 278.71 & 1519.14 & 277.91 & 1521.45 & 276.91 & 1521.45 & 276.91 \\
\hline $53 \mathrm{k} 7$ & 1479.76 & 260.10 & 1479.76 & 260.10 & 1481.77 & 258.18 & 1478.62 & 254.35 & 1481.27 & 252.82 & 1481.27 & 252.82 & 1481.27 & 252.82 \\
\hline $54 \mathrm{k} 7$ & 1598.66 & 306.19 & 1589.47 & 299.06 & 1589.47 & 299.06 & 1589.47 & 299.06 & 1589.47 & 299.06 & 1589.47 & 299.06 & 1592.63 & 298.20 \\
\hline $55 \mathrm{k} 9$ & 1561.79 & 300.18 & 1562.20 & 295.61 & 1559.07 & 291.02 & 1559.07 & 291.02 & 1559.07 & 291.02 & 1559.07 & 291.02 & 1559.07 & 291.02 \\
\hline $60 \mathrm{k} 9$ & 1810.80 & 341.70 & 811.85 & 332.92 & 1812.02 & 332.27 & 812.37 & 332.05 & 1814.61 & 330.64 & 1812.19 & 331.05 & 1816.56 & 328.40 \\
\hline $61 \mathrm{k} 9$ & 1482.53 & 238.98 & 1482.67 & 238.67 & 1483.19 & 235.77 & 83.19 & 235.77 & 1483.19 & 235.77 & 1483.19 & 235.77 & 1480.79 & 235.41 \\
\hline $62 \mathrm{k} 8$ & 1784.84 & 321.01 & 1784.93 & 317.34 & 1790.53 & 308.85 & 1790.52 & 306.72 & 1796.85 & 301.74 & 1796.09 & 302.40 & 1799.84 & 301.14 \\
\hline $63 \mathrm{k} 9$ & 2165.44 & 394.80 & 2165.87 & 387.57 & 2165.87 & 387.57 & 2167.06 & 386.64 & 2167.06 & 386.64 & 2167.14 & 386.61 & 2171.07 & 385.08 \\
\hline $63 \mathrm{k} 10$ & 1864.14 & 328.21 & 1865.51 & 320.98 & 1866.53 & 318.63 & 1866.53 & 318.63 & 1866.53 & 318.63 & 1866.53 & 318.63 & 1877.22 & 306.94 \\
\hline $64 \mathrm{k} 9$ & 1910.01 & 339.55 & 1904.71 & 329.92 & 906.08 & 327.95 & 1891.49 & 332.24 & 1881.62 & 333.65 & 1881.62 & 333.65 & 1881.62 & 333.65 \\
\hline $65 \mathrm{k} 9$ & 1713.51 & 289.57 & 1687.07 & 283.82 & 9.01 & 279.65 & 1689.06 & 279.47 & 1689.06 & 279.47 & 1689.06 & 279.47 & 1689.06 & 279.47 \\
\hline $69 \mathrm{k} 9$ & 1679.97 & 257.7 & 1673.71 & 252.81 & 1673.71 & 252.69 & 1673.71 & 252.69 & 1673.71 & 252.69 & 1673.71 & 252.69 & 1673.71 & 252.69 \\
\hline $80 \mathrm{k} 1 \mathrm{c}$ & 2361.55 & 379.39 & 2358.55 & 376.52 & 2321.71 & 377.51 & 2322.76 & 373.87 & 2322.76 & 373.87 & 2309.98 & 369.26 & 2325.75 & 360.13 \\
\hline
\end{tabular}

Table A.3: Impact of increasing $\beta$-values when there is congestion during the entire day and when the weather conditions are better. 


\begin{tabular}{|c|c|c|c|c|c|c|c|c|c|c|c|c|c|c|}
\hline set & & $=0.0$ & & 0.5 & & $=1.0$ & & $=1.5$ & & $=2.0$ & & $=2.5$ & $\beta=$ & 3.0 \\
\hline & $\mathrm{E}(\mathrm{TT})$ & $\mathrm{SD}(\mathrm{TT})$ & $\mathrm{E}(\mathrm{TT})$ & $\mathrm{SD}(\mathrm{TT})$ & $\mathrm{E}(\mathrm{TT})$ & $\mathrm{SD}(\mathrm{TT})$ & $\mathrm{E}(\mathrm{TT})$ & $\mathrm{SD}(\mathrm{TT})$ & $\mathrm{E}(\mathrm{TT})$ & $\mathrm{SD}(\mathrm{TT})$ & $\mathrm{E}(\mathrm{TT})$ & $\mathrm{SD}(\mathrm{TT})$ & $\mathrm{E}(\mathrm{TT})$ & $\mathrm{SD}(\mathrm{TT})$ \\
\hline $32 \mathrm{k} 5$ & 1209.10 & 491.09 & 1211.69 & 467.29 & 1215.05 & 458.84 & 1224.05 & 451.29 & 1224.05 & 451.29 & 1224.05 & 451.29 & 1224.05 & 451.29 \\
\hline $33 \mathrm{k} 5$ & 1023.06 & 381.46 & 1023.52 & 373.43 & 1024.67 & 372.34 & 1024.67 & 372.34 & 1024.67 & 372.34 & 1018.76 & 368.71 & 1018.76 & 368.71 \\
\hline $33 \mathrm{k} 6$ & 1154.92 & 451.00 & 1154.95 & 435.45 & 1155.41 & 434.83 & 1155.41 & 434.83 & 1155.41 & 434.83 & 1155.41 & 434.83 & 1155.41 & 434.83 \\
\hline $34 \mathrm{k} 5$ & 1200.86 & 447.89 & 1190.34 & 438.82 & 1193.64 & 432.68 & 1193.64 & 432.68 & 1197.92 & 429.13 & 1175.60 & 433.23 & 1175.60 & 433.23 \\
\hline $36 \mathrm{k} 5$ & 1311.28 & 519.92 & 1315.20 & 496.51 & 1316.84 & 476.54 & 1305.91 & 475.45 & 1305.91 & 475.45 & 1305.91 & 475.46 & 1307.23 & 466.82 \\
\hline $37 \mathrm{k} 5$ & 1062.79 & 367.51 & 1063.22 & 360.89 & 1063.22 & 360.89 & 1063.22 & 360.89 & 1063.22 & 360.89 & 1063.52 & 361.99 & 1063.52 & 361.99 \\
\hline $37 \mathrm{k} 6$ & 1480.21 & 569.43 & 1475.61 & 524.44 & 1466.38 & 517.28 & 1466.38 & 517.28 & 1466.38 & 517.28 & 1466.38 & 517.28 & 1466.38 & 517.28 \\
\hline $38 \mathrm{k} 5$ & 1154.69 & 410.38 & 1155.56 & 403.96 & 1157.26 & 399.15 & 1157.26 & 399.15 & 1159.97 & 395.21 & 1159.97 & 395.21 & 1164.63 & 393.48 \\
\hline $39 \mathrm{k} 5$ & 1278.98 & 456.96 & 1279.96 & 442.67 & 1279.96 & 442.67 & 1279.96 & 442.67 & 1279.96 & 442.67 & 1279.96 & 442.67 & 1279.96 & 442.67 \\
\hline 39 k6 & 1268.14 & 439.47 & 1268.73 & 434.45 & 1271.99 & 432.02 & 1275.79 & 427.27 & 1275.79 & 427.27 & 127 & & .26 & 422.16 \\
\hline $44 \mathrm{k} 6$ & 1474.87 & 468.45 & 1456.84 & 464.64 & 1456.84 & 464.64 & 1459.17 & 462.76 & 1459.17 & 462.76 & 1459.17 & 462.76 & 1459.17 & 462.76 \\
\hline $45 \mathrm{k} 6$ & 1416.26 & 458.27 & 1416.59 & 447.72 & 1416.59 & 447.72 & 1416.59 & 447.72 & 1425.47 & 441.76 & 1425.47 & 441.76 & 1425.47 & 441.76 \\
\hline $45 \mathrm{k} 7$ & 1679.00 & 580.85 & 1670.93 & 543.38 & 1671.28 & 542.30 & 1671.28 & 542.30 & 1671.28 & 542.30 & 1671.28 & 542.30 & 1693.81 & 534.36 \\
\hline $46 \mathrm{k} 7$ & 1431.58 & 470.80 & 1426.83 & 451.31 & 1426.83 & 451.31 & .83 & 451.31 & $142 t$ & 451 & 142 & 45 & 1426.83 & 451.31 \\
\hline $48 \mathrm{k} 7$ & 1601.30 & 543.07 & 1593.28 & 507.13 & 1596.20 & 500.21 & 1596.20 & 500.21 & 1596.20 & 500.21 & 1596.20 & 500.21 & 1596.20 & 500.21 \\
\hline $53 \mathrm{k} 7$ & 1559.86 & 474.43 & 1560.41 & 460.52 & 1560.41 & 460.52 & 1559.82 & 455.84 & 1559.82 & 455.84 & 1559.82 & 455.84 & 1559.82 & 455.84 \\
\hline $54 \mathrm{k} 7$ & 1679.84 & 544.59 & 1681.36 & 531.12 & 1684.93 & 528.06 & 1686.20 & 522.73 & 1683.87 & 526.54 & 1683.87 & 526.54 & 1683.87 & 526.54 \\
\hline $55 \mathrm{k} 9$ & 1654.26 & 551.41 & 1656.62 & 519.70 & 1656.62 & 519.70 & 1648.16 & 522.04 & 1648.16 & 522.04 & 1648.16 & 522.04 & 1654.15 & 498.13 \\
\hline $60 \mathrm{k} 9$ & 1905.26 & 603.73 & 1906.31 & 587.71 & 1909.48 & 587.27 & 1909.78 & 587.17 & 1912.15 & 583.26 & 1910.64 & 579.38 & 1910.64 & 579.38 \\
\hline 61 k9 & 1553.39 & 437.76 & 1554.89 & 430.21 & 1554.89 & 430.21 & 1554.89 & 430.21 & 1554.89 & 430.21 & 1560.46 & 424.52 & 1560.46 & 424.52 \\
\hline $62 \mathrm{k} 8$ & 1849.22 & 582.76 & 1849.79 & 556.67 & 1854.64 & 542.36 & 1863.70 & 531.64 & 1863.70 & 531.64 & 1863.70 & 531.64 & 1863.70 & 531.64 \\
\hline 63 k9 & 2275.69 & 692.33 & 2265.39 & 672.82 & 2265.39 & 672.82 & 2265.39 & 672.82 & 2269.73 & 670.06 & 2269.73 & 670.06 & 2269.73 & 670.06 \\
\hline $63 \mathrm{k}$ & 1956.34 & 565.01 & 1957.29 & 559.69 & 1934.31 & 552.99 & 34.31 & 552.99 & 1934.37 & 548.89 & 1934.37 & 89 & 1934.37 & 548.89 \\
\hline 64 k9 & 1996.03 & 609.47 & 1996.44 & 602.98 & 1990.09 & 593.41 & 1990.09 & 593.41 & 1990.09 & 593.41 & 1993.74 & 591.49 & 1993.74 & 591.49 \\
\hline 65 k9 & 1767.59 & 510.48 & 1768.36 & 497.92 & 1768.36 & 497.92 & 1768.36 & 497.92 & 1768.36 & 497.92 & 1768.36 & 497.92 & 1768.36 & 497.92 \\
\hline $69 \mathrm{l}$ & 1810.72 & 479 & 805.80 & 470.87 & 1805.80 & 470.87 & 1807.31 & 468.95 & 1790.02 & 464.84 & 1790.90 & 462.23 & 1790.90 & 462.23 \\
\hline $80 \mathrm{k} 10$ & 2460.95 & 731.84 & 2447.69 & 704.67 & 2447.94 & 704.24 & 2455.75 & 681.59 & 2478.90 & 648.08 & 2490.82 & 635.22 & 2490.82 & 635.22 \\
\hline
\end{tabular}

Table A.4: Impact of increasing $\beta$-values when there is a morning and evening congestion and when the weather conditions are bad. 


\begin{tabular}{|c|c|c|c|c|c|c|c|c|c|c|c|c|c|c|}
\hline set & & $=0.0$ & & $=0.5$ & & $=1.0$ & & $=1.5$ & & $=2.0$ & & $=2.5$ & & 3.0 \\
\hline & $\mathrm{E}(\mathrm{TT})$ & $\mathrm{SD}(\mathrm{TT})$ & $\mathrm{E}(\mathrm{TT})$ & $\mathrm{SD}(\mathrm{TT})$ & $\mathrm{E}(\mathrm{TT})$ & $\mathrm{SD}(\mathrm{TT})$ & $\mathrm{E}(\mathrm{TT})$ & $\mathrm{SD}(\mathrm{TT})$ & $\mathrm{E}(\mathrm{TT})$ & $\mathrm{SD}(\mathrm{TT})$ & $\mathrm{E}(\mathrm{TT})$ & $\mathrm{SD}(\mathrm{TT})$ & $\mathrm{E}(\mathrm{TT})$ & $\mathrm{SD}(\mathrm{TT})$ \\
\hline $32 \mathrm{k} 5$ & $\begin{array}{l}1098.19 \\
\end{array}$ & 253.85 & 1099.06 & 251.42 & 1099.06 & 251.42 & 1099.06 & 251.42 & 1099.06 & 251.42 & 1099.06 & 251.42 & 1099.06 & 251.42 \\
\hline $33 \mathrm{k} 5$ & 929.56 & 202.12 & 929.90 & 200.22 & 929.90 & 200.22 & 929.99 & 200.41 & 929.99 & 200.41 & 929.99 & 200.41 & 929.99 & 200.41 \\
\hline $33 \mathrm{k} 6$ & 1055.83 & 235.83 & 1055.83 & 235.83 & 1055.83 & 235.83 & 1055.83 & 235.83 & 1055.83 & 235.83 & 1056.46 & 235.51 & 1056.46 & 235.51 \\
\hline $34 \mathrm{k} 5$ & 1074.96 & 236.00 & 1075.13 & 235.66 & 1074.40 & 234.65 & 1074.40 & 234.65 & 1074.40 & 234.65 & 1074.40 & 234.65 & 1074.40 & 234.65 \\
\hline $36 \mathrm{k} 5$ & 1169.61 & 269.79 & 1171.29 & 253.23 & 1163.65 & 249.07 & 1163.65 & 249.07 & 1163.65 & 249.07 & 1163.65 & 249.07 & 1163.65 & 249.07 \\
\hline $37 \mathrm{k} 5$ & 1007.07 & 207.26 & 1007.73 & 203.63 & 1007.73 & 203.63 & 1007.73 & 203.63 & 1007.73 & 203.63 & 1006.62 & 201.02 & 1006.62 & 201.02 \\
\hline $37 \mathrm{k} 6$ & 1347.87 & 303.54 & 1347.97 & 301.08 & 1347.97 & 301.08 & 1348.12 & 282.06 & 1348.12 & 282.06 & 1348.12 & 282.06 & 1348.12 & 282.06 \\
\hline $38 \mathrm{k} 5$ & 1059.99 & 221.78 & 1055.67 & 220.38 & 1058.08 & 217.94 & 1058.08 & 217.94 & 1055.05 & 215.11 & 1057.56 & 213.10 & 1057.56 & 213.10 \\
\hline $39 \mathrm{k} 5$ & 1191.57 & 246.85 & 1191.57 & 246.85 & 1168.53 & 238.13 & 1168.53 & 238.13 & 1168.53 & 238.13 & 1168.53 & 238.13 & 1169.31 & 237.93 \\
\hline $39 \mathrm{k} 6$ & 1158.18 & 235.36 & 1158.35 & 234.62 & 1158.35 & 234.62 & 1163.36 & 230.90 & 1163.36 & 230.90 & 1163.36 & 230.90 & 1163.36 & 230.90 \\
\hline $44 \mathrm{k} 6$ & 1336.76 & 248.22 & 1336.76 & 248.22 & 1338.20 & 245.94 & 1338.20 & 245.94 & 1338.20 & 245.94 & 1338.20 & 245.94 & 1338.20 & 245.94 \\
\hline $45 \mathrm{k} 6$ & 1296.22 & 245.01 & 1296.26 & 244.92 & 1296.26 & 244.92 & 1303.00 & 239.07 & 1303.00 & 239.07 & 1303.00 & 239.07 & 1303.63 & 238.82 \\
\hline $45 \mathrm{k} 7$ & 1524.75 & 301.14 & 1524.75 & 301.14 & 1528.73 & 295.87 & 1528.73 & 295.87 & 1528.73 & 295.87 & 1525.47 & 292.61 & 1525.47 & 292.61 \\
\hline $46 \mathrm{k} 7$ & 1317.46 & 253.83 & 1303.27 & 246.60 & 1303.27 & 246.60 & 1303.35 & 246.62 & 1303.35 & 246.62 & 1303.35 & 246.62 & 1303.88 & 244.84 \\
\hline $48 \mathrm{k} 7$ & 1475.72 & 285.97 & 1469.79 & 277.09 & 1470.25 & 276.29 & 470.25 & 276.29 & 1473.89 & 269.00 & 1464.84 & 268.52 & 1462.92 & 268.34 \\
\hline $53 \mathrm{k} 7$ & 1425.89 & 255.53 & 1422.99 & 247.54 & 1422.99 & 247.54 & 1424.85 & 245.74 & 1424.85 & 245.74 & 1424.85 & 245.74 & 1424.85 & 245.74 \\
\hline $54 \mathrm{k} 7$ & 1543.82 & 299.34 & 1531.01 & 292.22 & 1535.67 & 285.59 & 1535.67 & 285.59 & 1535.67 & 285.59 & 1536.03 & 284.65 & 1536.03 & 284.65 \\
\hline $55 \mathrm{k} 9$ & 1503.57 & 283.37 & 1503.63 & 279.63 & 1503.63 & 279.63 & 1503.63 & 279.63 & 1503.63 & 279.63 & 1508.09 & 277.94 & 1508.09 & 277.94 \\
\hline $60 \mathrm{k} 9$ & 1752.58 & 334.74 & 1753.24 & 319.49 & 1753.24 & 319.49 & 1753.75 & 319.10 & 1753.79 & 319.24 & 1755.37 & 315.90 & 1765.02 & 308.92 \\
\hline $61 \mathrm{k} 9$ & 1423.89 & 233.74 & 1423.91 & 233.52 & 1424.35 & 233.02 & 1424.35 & 233.02 & 1425.47 & 228.81 & 1425.47 & 228.81 & 1425.47 & 228.81 \\
\hline $62 \mathrm{k} 8$ & 1702.10 & 313.64 & 1691.52 & 299.21 & 1691.92 & 298.20 & 1691.08 & 297.31 & 1691.08 & 297.31 & 1697.78 & 293.93 & 1703.88 & 291.81 \\
\hline $63 \mathrm{k} 9$ & 2091.36 & 371.07 & 2091.69 & 367.72 & 2092.75 & 365.25 & 2069.67 & 363.60 & 2076.06 & 356.71 & 2079.58 & 354.08 & 2079.58 & 354.08 \\
\hline $63 \mathrm{k} 10$ & 1787.76 & 307.46 & 80.89 & 303.37 & 1781.08 & 300.04 & 1781.41 & 299.79 & 1781.41 & 299.79 & 1773.87 & 300.71 & 1773.87 & 300.71 \\
\hline $64 \mathrm{k} 9$ & 1837.35 & 323.25 & 1828.93 & 322.04 & 828.93 & 322.04 & 29.01 & 321.97 & 1829.60 & 321.70 & 1824.53 & 316.38 & 1824.53 & 316.38 \\
\hline $65 \mathrm{k} 9$ & 1629.06 & 279.81 & 1625.67 & 276.61 & 1625.67 & 276.61 & 1627.98 & 275.41 & 1627.98 & 275.41 & 1628.75 & 274.50 & 1628.75 & 274.50 \\
\hline $69 \mathrm{k} 9$ & 1637.35 & 253.8 & 1637.24 & 248.69 & 1637.24 & 248.84 & 1637.24 & 248.84 & 1637.24 & $24 \varepsilon$ & 1616.36 & 246.08 & 1616.46 & 246.22 \\
\hline $80 \mathrm{k} 10$ & 2224.19 & 370.38 & 2221.44 & 371.72 & 2226.50 & 364.06 & 2226.50 & 364.06 & 2252.29 & 346.53 & 2252.29 & 346.53 & 2252.49 & 346.37 \\
\hline
\end{tabular}

Table A.5: Impact of increasing $\beta$-values when there is a morning and evening congestion and when the weather conditions are better. 


\section{References}

[1] E. H. L. Aarts and J.K. Lenstra. Local Search in Combinatorial Optimization. Wiley, 1997.

[2] N. C. Beaulieu and Q. Xie. An optimal lognormal approximation to lognormal sum distributions. IEEE Transactions on Vehicular Technology, 53(2):479-489, 2004.

[3] D.S. Berry and D.M. Belmont. Distribution of vehicle speeds and travel times. Proc. 2nd Berkeley Sympos. Math. Statist. Probab., pages 589-602, 1951.

[4] M.J. Best and R.R. Grauer. Sensitivity analysis for mean-variance portfolio problems. Management Science, 37(8):980-989, August 1991.

[5] C. Chen, E. van Zwet, P. Varaiya, and A. Skabardonis. Travel time reliability as a measure of service. Technical report, Transporation Research Board, 2003.

[6] A.V. Donati, R. Montemanni, N. Casagrande, A.E. Rizzoli, and L.M. Gambardella. Time dependent vehicle routing problem with a multi ant colony system. Technical Report IDSIA -02-03, International IDSIA, 2003.

[7] A. M. Finkel. A simple formula for calculating the mass density of a lognormally-distributed characteristic: Applications to risk analysis. Risk Analysis, 10(2):291-301, 1990.

[8] L. Fu and L.R. Rilett. Expected shortest path in dynamic and stochastic traffic networks. Transportation Research Record, 32(7):499-516, 1998.

[9] S. Gao and I. Chabini. The best routing policy problem in stochastic timedependent networks. Transportation Research Record, 1783:188-196, 2002.

[10] S. Gao and I. Chabini. Optimal routing policy problem in stochastic timedependent networks. Transportation Research B, 40:93-122, 2006.

[11] M. Gendreau, A. Hertz, and G. Laporte. A tabu search heuristic for the vehicle routing problem. Management Science, 40(10):1276-1290, 1994.

[12] M. Gendreau, G. Laporte, and R. Séguin. Stochastic vehicle routing. European Journal of Operational Research, 88(1):3-12, 1996.

[13] M. Gendreau, G. Laporte, and R. Séguin. A tabu search heuristic for the vehicle routing problem with stochastic demands and customers. Operations Research, 44(3), 1996.

[14] B.E. Gillett and L.R. Miller. A heuristic algorithm for the vehicle-dispatch problem. Operations Research, 22(2):340-349, 1974.

[15] F. Glover. Tabu search, part. ORSA Journal of Computing, pages 190-206, 1989.

[16] F. Glover. Tabu search, part II. ORSA Journal of Computing, pages 4-32, 1990. 
[17] R.R. Grauer and N.H. Hakansson. On the use of mean-variance and quadratic approximations in implementing dynamic investment strategies: A comparison of returns and investment policies. Management Science, 39(7):856-871, July 1993.

[18] A. Haghani and S. Jung. A dynamic vehicle routing problem with timedependent travel times. Computers and Operations Research, 32:2959-2986, 2005.

[19] R.W. Hall. The fastest path through a network with random timedependent travel times. Transportations Science, 20(3):182-188, 1986.

[20] R.R. He, A.L. Kornhauser, and B. Ran. Essentially best routes in dynamic and stochastic transportation network. International Journal of Vehicle Information and Communication Systems, 1(1-2):1-14, 2005.

[21] D. Heidemann. A queueing theory approach to speed-flow-density relationships. In Proceedings of the 13th International Symposium on Transportation and Traffic Theory, Lyon, France, 1996. Transporation and traffic theory.

[22] A. Hertz, G. Laporte, and M. Mittaz. A tabu search heuristic for the capacitated arc routing problem. Operations Research, 48(1):129-135, 2000.

[23] S. Ichoua, M. Gendreau, and J-Y. Potvin. Vehicle dispatching with time-dependent travel times. European Journal of Operational Research, 144:379-396, 2003.

[24] Rockwell Software Inc. Arena User's Guide. Rockwell Software Inc., 2005.

[25] R. Jain and J. MacGregor Smith. Modeling vehicular traffic flow using M/G/C/C state dependent queueing models. Transportation Science, 31:324-336, 1997.

[26] A.S. Kenyon and D.P. Morton. Stochastic vehicle routing with random travel times. Transportation Science, 37(1):69-82, 2003.

[27] J. P. Kharoufeh and N. Gautam. Deriving link travel-time distributions via stochastic speed processes. Transportation Science, 38(1):97-106, February 2004.

[28] J. Kwon, B. Coifman, and P. Bickel. Day-to-day travel time trends and travel-time prediction from loop-detector data. Transportation Research Record, 1717:120-129, 2000.

[29] G. Laporte. The vehicle routing problem: An overview of exact and approximate algorithms. European Journal of Operational Research, 59(3):345358, 1992.

[30] G. Laporte, F. Louveaux, and H. Mercure. The vehicle routing problem with stochastic travel times. Transportation Science, 26(3):161-170, 1992.

[31] C. Malandraki and M.S. Daskin. Time dependent vehicle routing problems: Formulations, properties and heuristic algorithms. Transportation science, 26(3):185-200, 1992. 
[32] J.M. Mulvey, R.J. Vanderbei, and S.A. Zenios. Robust optimization of large-scale systems. Operations Research, 43(2):264-281, March-April 1995.

[33] A. Papoulis. Probability, Random Variables and Stochastic Processes. McGraw-Hill, 1991.

[34] M. Pirlot. General local search methods. European Journal of Operational Research, 92:493-511, 1996.

[35] E. Taniguchi, R.G. Thompson, T. Yamada, and R. Van Duin. City Logistics: Network Modelling and Intelligent Transport Systems. Pergamon, 2001.

[36] N. Vandaele, T. Van Woensel, and A. Verbruggen. A queueing based traffic flow model. Transportation Research D, 5(2):121-135, February 2000.

[37] N.J. Vandaele. The Impact of Lot Sizing on Queueing Delays: Multi Product, Multi Machine Models. PhD thesis, Katholieke Universiteit Leuven, Department of Applied Economics, 1996.

[38] W. Whitt. The queueing network analyzer. The Bell System Technical Journal, 62(9):2779-2815, 1983.

[39] T. Van Woensel. Modelling Uninterrupted Traffic Flows, a Queueing Approach. Ph.D. Dissertation, University of Antwerp, Belgium, 2003.

[40] T. Van Woensel, R. Creten, and N. Vandaele. Managing the environmental externalities of traffic logistics: The issue of emissions. POMS journal, Special issue on Environmental Management and Operations, Vol.10, nr. 2, Summer 2001, 2001.

[41] T. Van Woensel, L. Kerbache, H. Peremans, and N. Vandaele. Vehicle routing with dynamic travel times: A queueing approach. Under Review, 2006.

[42] T. Van Woensel, L. Kerbache, H. Peremans, and N. Vandaele. A queueing framework for routing problems with time-dependent travel times. Journal of Mathematical Models and Algorithms, Special Issue "Quantitative aspects of transportation and logistics", 6(1):151-173, 2007.

[43] T. Van Woensel and N. Vandaele. Empirical validation of a queueing approach to uninterrupted traffic flows. 4OR, A quarterly Journal of Operations Research, 4(1):59-72, 2006.

[44] T. Van Woensel, B. Wuyts, and N. Vandaele. Validating state-dependent queueing models for uninterrupted traffic flows using simulation. 4OR, $A$ quarterly Journal of Operations Research, 4(2):159-174, 2006. 